WAPD-TM-1382

DOE Research and Development Report

\title{
Arc Modeling for Welding Analysis
}

S. S. Glickstein

Betfls Atomic Power Laboratory

West Mifflin, Pennsylvania 15122

April 1978

Prepared for the

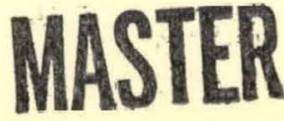

U.S. Department of Energy

(27) By Westinghouse Electric Corporation

Under Contract No. EY-76-C-11-0014 


\section{DISCLAIMER}

This report was prepared as an account of work sponsored by an agency of the United States Government. Neither the United States Government nor any agency Thereof, nor any of their employees, makes any warranty, express or implied, or assumes any legal liability or responsibility for the accuracy, completeness, or usefulness of any information, apparatus, product, or process disclosed, or represents that its use would not infringe privately owned rights. Reference herein to any specific commercial product, process, or service by trade name, trademark, manufacturer, or otherwise does not necessarily constitute or imply its endorsement, recommendation, or favoring by the United States Government or any agency thereof. The views and opinions of authors expressed herein do not necessarily state or reflect those of the United States Government or any agency thereof. 


\section{DISCLAIMER}

Portions of this document may be illegible in electronic image products. Images are produced from the best available original document. 
ARC MODELING FOR WELDING ANALYSIS

\section{S. S. GLICKSTEIN}

Contract No. EY-76-C-11-0014

Apri1 1978
This repon was prepared as an account of work ponsored by the United States Govemment. Neither the United States nor the United States Department of Energy, nor any of their employees, nor any of their contractors, subcontractors, or their employees, makes any warranty, express or implied, or assumes any legal liability or responsibility for the accuracy, completeness or usefulness of any information, apparatus, product or process disclosed, or represents that its use would not infringe privately owned rights.

Printed in the United States of America Avallable from the National Technical Information Service

U. S. Department of Commerce 5285 Port Royal Road Springfie1d, Virginia 22151

\section{NOTE}

Th1s document 18 an interim memorandum prepared primarily for internal reference and does not represent a final expression of the opinion of Westinghouse. When this memorandum is distributed externally, it is with the express understanding that Westinghouse makes no representation as to completeness, accuracy, or usability of information contained therein. 


\section{NOTICE}

This report was prepared as an account of work sponsored by the United States Government. Neither the United States, nor the United States Department of Energy nor any of their employees, nor any of their contractors, subcontractors, or their employees, makes any warranty, express or implied, or assumes any legal liability or responsibility for the accuracy, completeness or usefulness of any information, apparatus, product or process disclosed, or represents that its use would not infringe privately owned rights. 
Arc Modeling for Welding Analysis

S. S. Glickstein

Abstract

A one-dimensional model of the welding arc that considers heat generation by the Joule effect and heat losses by radiation and conduction has been used to study the effects of various gases and gas mixtures currently employed for welding applications. Minor additions of low lonization potential impurities to these gases are shown to significantly perturb the electrical properties of the parent gas causing gross changes in the radial temperature distribution of the arc discharge. Such changes are reflected in the current density distribution and ultimately in the input energy distribution to the weldment. The result is observed as a variation in weld penetration.

Recently published experiments and analyses of welding arcs are also evaluated and shown to contain erroneous data and results. Contrary to previous beliefs, the inclusion of a radiation 1088 term in the basic energy balance equation is important and cannot be considered as negligible in an argon arc at temperatures as low as $10000 \mathrm{~K}$.

The one-dimensional analysis of the welding are as well as the evaluation of these earlier published reports helps to explain the effects of various gases used for welding, improves our understanding of the physics of the welding arc, and provides a stepping stone for a more elaborate model which can be applied to help optimize welding parameters. 
Arc Modeling for Welding Analysis

S. S. Glickstein

PAGE

I. Introduction.................................. 1

II. Calculational Model.............................. 2

1. Conservation Equations......................... 2

2. Electric Field.............................. 5

3. Electrical and Thermal Conductivity............... 6

4. Radiation................................... 7

III. Analytical Results............................. 7

1. Evaluation of Radiation Effects.................. 7

2. Argon-Helium Mixtures.......................... 9

3. Helium and Argon Arcs Containing Minor Amounts of Aluminum.................................... 12

4. Analyses of Temperature Distribution Measurements.... 15

a. Data of Gick, Quigley and Richards.............. 15

b. Data of Evans and Tank1n..................... 16

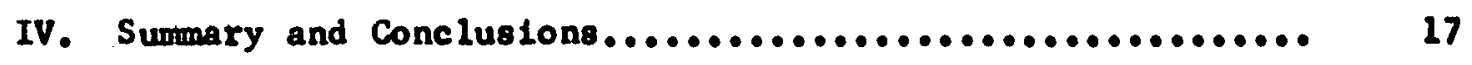

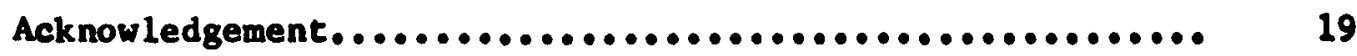

References..................................... 20

Figures..................................... 22

Append $1 x \ldots \ldots \ldots \ldots \ldots \ldots \ldots \ldots \ldots \ldots \ldots \ldots \ldots \ldots \ldots \ldots \ldots \ldots \ldots \ldots \ldots \ldots \ldots . \ldots \ldots$ 


\section{Arc Modeling For Welding Analysis}

S. S. Glickstein

\section{Introduction}

Within the next decade the electric arc as applied to welding applications will approach its centennial celebration(1). During these past one hundred years, considerable progress has been made toward achieving welds with a high degree of perfection. This has been accomplished as a result of expending considerable experimental effort devoted to welding development. with the theoretical justification playing a secondary role. In addition, part of the success in today's welding operations can be attributed to the built in feedback mechanism that is present when welding is performed manually. But as modern technology progresses, and automated machinery replaces the manual welder, the natural feedback between the welding operation and the operator becomes lost, and instantaneous corrective action that is sometimes necessary during welding can no longer be accomplished. At this stage of development, it becomes extremely important that the welding process be better understood from a theoretical point of view.

As a means of furthering our understanding of the Gas Tungsten Arc Welding (GTAW) process, the arc discharge and energy distribution to the weldment are analyzed using a one-dimensional analytical model of the arc. In particular, arc temperature and current density distributions are calculated and analyzed for helium and argon arcs as well as for arcs containing various mixtures of these gases. These gases are commonly used in welding applications. Knowledge of the cemperature and current distributions in the welding arc are important in order to predict the heat transfer, metallurgical structure, weld penetration, and ultimately residual stresses and distortions 
within the weldment. Variations of the input energy distribution to the weldment have previously been shown through analytical studies to significantly affect the width and depth of the weld(2).

Vapors of minor elements, such as aluminum entering the shielding gas via emission from a stainless steel weld plate, have been visually observed to change the arc configuration and penetration(3). Qualitative explanations have been made to justify such behavior(4), but a quantitative analyois has never been presented. Employing the physical properties of gases containing mixtures of aluminum and argon, aluminum and helium, as well as argon and helium, the analytical model of the arc is used to demonstrate the effects of minute additions of minor elements to the welding gas on the arc discharge.

Although considerable experimental and theoretical effort has been applied toward understanding the physics of arc discharges, limited work has been devoted directly to the welding arc. Recently reported temperature distribution measurements of a $100 \mathrm{~A}$ welding arc(5) are analyzed and shown to be incompatible with results of the analytical model. This report also analyzes the effects of radiation in argon arcs and finds this to be an important contribution to the energy balance equation at arc temperatures considerably smaller than those reported previously $(6,7)$.

The application of the arc model described in this report has provided considerable insight into and understanding of the effects of gaseous properties on the welding arc. It is a stepping stone for a more elaborate and sophisticated treatment of the arc discharge which can eventually be applied to help optimize welding parameters. 


\section{Calculational Model of the Arc}

The welding arc whose electrode (cathode) is far from the weldment (anode) is illustrated in Figure 1. Three distinct regions are present; the anode drop region, plasma column, and cathode drop region. While the cathode and anode drop regions are of prime importance in an analysis of the welding arc, their complexity leads one to consider the far simpler region, the plasma column for an initial analysis. The difficulty in considering the electrode regions can be attribuced to experimental observations of current densities from several to hundreds of millions of $\mathrm{A} / \mathrm{cm}^{2}$, both in single spots, and with separation into hundreds of individual spots. The temperature of the spots far exceed the boiling point, and extreme velocity values in normal and reverse directions are a common phenomenon for this region(8). The plasma region which is simpler to analyze provides an excellent basis for understanding effects on the arc and we ldment that can be attributed to gaseous impurities in the arc, welding current and arc voltage. These factors may be influenced by both the type gas and electrode configuration. Thus, the following analysis will be concerned primarily with the column region of an arc.

\section{Conservation Equations}

To formulate a solution for the current, temperature, pressure, and gas flow in the plasma region of an arc (See Figure 1), the following conservation equations must be satisfied.

Conservation of mass

$$
\operatorname{div}(\rho \bar{v})=0
$$

Conservation of momentum

$$
\rho \frac{\mathrm{d} \overline{\mathrm{v}}}{\mathrm{dt}}=\operatorname{grad} p+\frac{1}{\mathrm{c}} \overline{\mathrm{J}} \times \overline{\mathrm{H}}
$$


Conservation of energy

$$
\operatorname{div}(k \operatorname{grad} T)-\rho \bar{v} \cdot \operatorname{grad} h+\sigma E^{2}-U=0
$$

Conservation of current

$$
\operatorname{div} \bar{j}=0
$$

where

$$
\begin{aligned}
& \rho=\text { mass density } \\
& \bar{v}=\text { flow velocity } \\
& \bar{p}=\text { pressure } \\
& c=\text { velocity of light } \\
& \overline{\mathbf{J}}=\text { current density } \\
& \mathbf{T}=\text { temperature } \\
& \mathbf{h}=\text { enthalpy } \\
& \mathbf{k}=\text { thermal conductivity } \\
& \sigma=\text { electrical conductivity } \\
& \overline{\mathrm{H}}=\text { self-magnetic field } \\
& \mathrm{E}=\text { electric field strength } \\
& \mathbf{v}=\text { radiated power per unit volume }
\end{aligned}
$$

In addition, boundary conditions need to be specified for a complete solution to be obtained for the above equations.

A considerable simplification of the solution of the problem is possible by assuming the gas to be strictly immobile. This neglects any forced motion due to the applied and self-generated electric and magnetic fields as well as any kind of natural convection or end effects due to the electrodes. While such an assumption may be unrealistic, it nevertheless enables one to understand the effects of the thermal and electrical properties of the gas on the temperature and current density distributions in the 
arc. The model for the column region of the arc may then be expressed very simply by the energy conservation equation in the radial direction only.

$$
\sigma E^{2}-U=-\frac{1}{r} \cdot \frac{d}{d r}\left(r k \frac{d T}{d r}\right)
$$

The total current I is given by

$$
I=\int_{0}^{\infty} 2 \pi x \cdot f(r) d r
$$

where the current density $f(r)$ is given by

$$
j(x)=\sigma(T) E
$$

The solution to equation 5 requires a knowledge of the electric fleld $E$; temperature dependent electrical conductivity $\sigma(T)$, temperature dependent thermal conductivity $k(T)$ and temperature dependent radiation 1088 term $U(T)$. The appropriate evaluation of these parameters is discussed in the next section. The solution to equations (5-7) was performed with a computer analysis using the Fortran program COLMN formulated by Chou(9). Minor improvements to the program were made in order to procure graphical output and to obtain solutions for fixed current arcs.

\section{Electric Fleld}

The electric field for argon, helium, and mixtures of these gases were found experimentally by determining the arc plasma voltage $v_{p}$, as a function of arc gap spacings. From such data, the E field is simply given by,

$$
E=\frac{d V_{p}}{d z}
$$

As previously discussed in Reference 10 , the are plasma voltage $V_{p}$ is deduced from the measured voltage $v_{m}$ which includes the potential drops in 
the line $V_{L}$ and electrode $V_{e}$. Typical measured results are shown in Figure 2. The zero arc gap intercept in Figure 2 is a measure of the sum of the anode drop $v_{a}$, and cathode drop $v_{c}$ (See Figure 1). This sum, $v_{a}+v_{c}$ as well as the electric field E, for various mixtures of argon and helium gases are shown in Figure 3 for a $100 \mathrm{~A}$ welding arc. The $\mathrm{E}$ field evaluation is in reasonable agreement with previously reported measurements given in Reference 11. From these data, it is readily observed that small additions of argon gas to helium drastically alters the magnitude of the electric field while small additions of helium to argon have little effect. This can he understood in terms of the ionization potentials and the electrical properties of these gases and is discussed in the next section.

\section{Electrical and Thermal Conductivity}

Electrical and thermal conductivities of gases were calculated by R. W. Liebermann; Westinghouse Research Laboratory with the method described in Reference 12. The results for air, argon, helium, mixtures of argon and helium as well as mixtures of aluminum-helium and aluminum-argon are presented in Figures 4-11. Readily evident in these figures is the significant effect small additions of aluminum vapor have on the electrical conductivicy of both argon and helium gases at temperatures below $12000 \mathrm{~K}$ (Figures 6, 7). The small addition of argon to helium also produces a large change in the electrical conductivity of helium (Figure 10). This is attributed to the differences in ionization potential (IP) of these elements (IP(A) $=15.08 \mathrm{eV}$, IP(He) $24.46 \mathrm{eV}, \operatorname{IP}(\mathrm{Al})=5.96 \mathrm{eV}$ ) which predominantly affect the degree of ionization present in each of these elements at low temperatures. (See Figures $12 a, 12 b, 12 c)$. The degree of ionization relates directly to the electrical conductivity of the gas. At temperatures near $20000 \mathrm{~K}$ all three gases are 
completely ionized and the effects of one gas on the other is negligible. The thermal conductivities of both helium and aluminum are greater that that of argon. Thus, any addition of either of these two gases to argon increases the effective thermal conductivity of the mixture relative to pure argon:

4. Radiation

The radiation term $U$, in Equation (5) represents quantic emission of all the relevant spectral lines from the various species of gases and impurities (13). Figure 13 illustrates the different type radiative transitions that may occur in atoms which contribute to the radiative power. The total power $U$ is given by the summation over the bound-bound transitions $U_{b b}$; free-bound transition $U_{f b}$, and free-free transitions $U_{f f}$.

$$
\mathrm{u}=\mathrm{u}_{\mathrm{bb}}+\mathrm{u}_{\mathrm{fb}}+\mathrm{u}_{\mathrm{ff}}
$$

A calculational analysis of the total power $U$ for an argon arc was performed and detailed in Appendix I. The poor agreement of the results with experimentally published values has been attributed to limitations in the calculational technique. As a result, the experimental radiation data of Evans and Tankin (14) was used exclusively in the calculational model for evaluating the effects of the radiation term on the temperature and current density distributions of an argon discharge.

\section{Analytical Results}

1. Evaluation of Radiation Effects

The relative magnitude of the energy source term $\sigma(T) E^{2}$ for argon as a function of arc temperature for various electric fields is illustrated In Figure 14, and compared to the measured radiation emission results of 
Evans and Tankin(14) for a 100A arc. As noted from the measured results shown in Figure 15, a reasonable estimate of the average electric field for argon is on the order approximately $8 \mathrm{~V} / \mathrm{cm}$. For such values of the E field, - arc temperatures above approximately 13 000K become physically unreal in a one-dimensional arc model, since the radiation loss is greater than the energy input (See Figure 14). While such results are consistent for low temperature arcs $(5,15)$, two dimensional heat transfer is necessary to explain the occurrence of arc temperatures greater than $13000 \mathrm{~K}$ reported for higher current arcs $(16,17)$. In this case, an axially varying $E$ field and axial heat transfer which are neglected in the one-dimensional arc model can be included. In such a model higher arc temperatures may be accommodated without violating the conservation of energy in the arc.

The effects of including a radiation term in equation 5 are very significant. For example, the temperature and current density distributions for a $100 \mathrm{~A}$ argon arc with and without a radiation term are shown in Figures 16 and 17 respectively. The radiation emission data of Evans and Tankin(14) were used but reduced by $50 \%$ in order that the energy production term $\mathrm{E}^{2}$ be greater than the energy 1088 (See Appendix I). This is physically realistic if one assumes that the arc is not optically thin, and self absorption of the emitted radlation is significant. Since radiation losses are proportionately greater at higher temperatures the effect is to flatten the heat source distribution near the axis. The result is a reduction in the peak temperature and current density on the axis, and a broadening of both the temperature and current density distributions by almost 50\%. This simplified analysis reveals the importance of considering radiation lossẹs when evaluating the temperature distribution in welding arcs. The effect of radiation can be neglected only when the temperature is below approximately 10 000K. This 18 the case for very low current arcs or for arcs dominated by vapor emission from the weldment. 
The same experimental radiation emission data was used by previous investigators $(6,7)$ to study radiation effects in argon arcs. These investigators falled to note that the radiation was given per unit $8011 d$ angle. The magnitude of argon radiation used in their analybis was therefore a factor of $4 \pi$ too small. As a result, it was errneously concluded that radiation effects could be considered negligible for a $100 \mathrm{~A}$ arc.

2. Argon-Helium Mixtures

As previously stated, due to the large difference in ionization potential between argon and helium the electrical conductivity of argon is significantly larger than that of helium at low temperatures. The large mass difference between argon and hellum accounts for the thermal conductivity of helium being much greater than that of argon. The effect of these physical parameters in the current and temperature distributions in an arc contalning various mixture ratios of argon and hellum are now discussed. Pigure 18 shows the calculated radial temperature distribution for pure helium and pure argon arcs. The $E$ fleld used for the hellum arc was $15 \mathrm{~V} / \mathrm{cm}$, and for the argon arc $7.7 \mathrm{~V} / \mathrm{cm}$, as determined from the measurements discussed previously. Equation 5 , with the radiation term set equal to zero was used to determine the temperature distribution as it is effected by the transport properties only. The larger electric field and higher thermal condcutivity of helium results in a much broader and higher arc discharge temperature distribution than that for a comparable argon arc. The E field produces a larger energy source term, $\sigma \mathrm{E}^{2}$, and the h1gher thermal conductivity increases the radial energy transfer. Although the temperature distribution for helium is much broader than argon, the current density distributions shown in Figure 19 have about the same cutoff radius. 
This can readily be understood by examining the temperature dependence of the electrical condcutivity for these two gases shown in Figure 4. The current density $f(j \neq \sim E)$ may be assumed to be negligible below a value of approximately $1(\mathrm{ohm}-\mathrm{cm})^{-1}$. Thus, from Figure $4, \mathrm{j}=0$ at a temperature below approximately $6000 \mathrm{~K}$ for argon and approximately $11000 \mathrm{~K}$ for hellum. For a $100 \mathrm{~A}$ arc, this occurs at a radius of approximately $0.3 \mathrm{~cm}$ for both argon and helium (See Figure 18) which helps explain the current density distribution curves for helium and argon arcs shown in Figure 19.

It has previously been established $(18,19)$ that the radiative and convective energies constitute a small fraction of the total energy supplied to the weldment; the major contribution is from the kinetic energy carried by the electron current. Thus, the current density distribution effectively determines the input energy distribution to the weldment. The total energy input $Q$ is given by (18).

$$
u=i\left(v_{a}+v_{K T}+v_{w}^{\prime}\right)
$$

where

$$
\begin{aligned}
V_{a} & =\text { anode voltage drop } \\
V_{w} & =\text { anode work function } \\
V_{K T} & =\text { thermal energy in plasma }
\end{aligned}
$$

Typical values for these terms may be considered as follows: $\mathrm{v}_{\mathrm{a}}$ approximately $3 \mathrm{eV}, \mathrm{v}_{\mathrm{w}}$ approximately $4.5 \mathrm{eV}, \mathrm{V}_{\mathrm{KT}}$ approximately $1.2 \mathrm{eV}$. The thermal energy from the arc plasma $I V_{K T}$ is a small fraction of the total energy (1.2I vs 8.7I). Thus, perturbations of a few thousand degrees $K$ in the absolute temperature of the arc which is on the order of $11000 \mathrm{~K}$ do not affect the total energy input $(11000 \mathrm{~K}=1 \mathrm{eV})$. 
To understand why welding with helium produces so much more energy than welding with argon at the same current, the difference in anode drop voltage of these two gases must be compared. Pigure 2 shows the results of the anode plus cathode drop potential for pure argon, helium, and mixtures of these gases. The ratio of cathode drop potential to anode drop potential has been shown to be approximately 1.8 in an argon discharge(20). Assuming the ratio to be the same for a helium discharge, the total input energy $Q$ for helium and argon arc can be expressed from equation (10), as follows (See Figure 3):

$$
\begin{aligned}
& Q_{A}=I(2.99+1.2+4.5)=8.69 I \\
& Q_{H e}=I(4.71+1.2+4.5)=10.41 I
\end{aligned}
$$

Thus, for the same arc current, the input energy is approximately 20\% larger for a helium than for an argon discharge.

It is a misconception to think that by increasing the current of an argon arc so that the total power will be equal to that in a helium arc, the resultant welds will be equivalent. This can be understood from the following example.

If total power $P$ is calculated from the commonly assumed formula $P=I V$, where $V$ is the recorded arc voltage, then for the same current, the heltum arc input energy $1850 \%$ greater than the input energy for a comparable argon arc. This is because the helium arc voltage is approximately 1.5 times the argon arc voltage.

In order to input the same total power with an argon arc as with an helium arc, it would be necessary to increase the current in the argon arc by a factor of 1.5. The calculated power distribution for two such arcs is shown in Figure 20. The results show a higher peak power density for helium 
than for argon. Under such conditions, it has previously been shown analytically. that a deeper weld puddle will be obtained in agreement with experimental observations that welding with helium provides a more penetrating arc than argon.

3. Helium and Argon Arcs Containing Minor Amounts of Aluminum Experimental results by Bennet and Mills(3) revealed that aluminum vapor present in an argon arc during the welding of high manganese stainless steel significantly perturbed the arc configuration and affected weld penetration. Recent attempts by Metcalfe and Quigley(21) to verify these experiments have been unsuccessful. No satisfactory explanation for these differing results has as yet been forthcoming. Because of this, it was deemed desirable to study the affects of minor amounts of aluminum vapor on the configuration and current density of both argon and helium arcs. Calculated thermal and electrical conductivities for different atom ratios (between $10^{4}$ and $10^{1}$ of He/Al and $\mathrm{A} / \mathrm{Al}$ are shown in Figures 6 and 7. As previously mentioned, the addition of aluminum to both helium and argon gases has a profound effect on their electrical conductivities as a result of the relatively low lonization potential of aluminum compared to that of helium and argon. Thus, the main source of free electrons for current conductance at low arc temperatures must be attributed to the high degree of Ionization of aluminum in the gas mixture.

The eplenlated radinl temperature and curront deneity diotributiono for a columnated arc containing these various gaseous mixtures are shown In Figures 21-24. Again, the radiation term in equation 5 was set equal to zero in order to concentrate on the effects of the electrical and thermal conductivities. The effect is more pronounced for the helium arc because 
of the strong Influence of aluminum on the electrical conductivity of the He-Al mixture. For example, in a mixture where the He/Al ratio equals 10, at $10000 \mathrm{~K}$, only $0.004 \%$ of the helium gas is ionized while more than $99.9 \%$ of the aluminum gas is singly, doubly or triply ionized. Again, this is a result of the low Ionization potential of aluminum relative to hellum.

As small quantities of aluminum gas are added to helium (i.e. $\mathrm{He} / \mathrm{Al}-10^{3}$ ), the initial effect is to create a significant thermal energy source term $\sigma E^{2}$, in the low temperature region $(5000 \mathrm{~K}$ to $10000 \mathrm{~K})$. This term is negligible with smaller amounts of aluminum. Such an energy source in the periphery of the arc tends to spread the arc temperature distribution. Since current can now flow through the low temperature region (recall that the current density $f=\sigma(T) E$ ) because of an appreclable electrical conductivity at low temperatures, the current density at the center of the arc w11 decrease if the total current is to remain the same. For this to occur, a decrease in the peak temperature of the arc is necessary. This is precisely what is observed and is Illustrated in Figure $2 i$.

The effects of further additions of aluminum toward a mixture ratio. of $\mathrm{He} / \mathrm{Al}=10$ acts to contract the arc. Again, this can be explained in terms of the transport properties of the gas. As the He/Al ratio increases, the electrical conductivity increases significantly while the thermal conductivicy remains relatively unaffected in the temperature range of interest (See Figures 5 and 7 ). Since the current density increases proportionately to the electrical conductivity, the arc contracts in order to conserve the total current. This effect can readily account for the seemingly ambiguous results of investigators who have reported observing sometimes contracting and sometimes expanding arcs during welding. 
For an argon arc, such effects are less dramatic when the arc temperature is high, as for example in the 100 amp arc shown in Figure 23. This too can be understood upon examination of the temperature dependence of the electrical and thermal conductivities $\sigma$ and $k$ (Pigures 6 and 8). As minor. additions of aluminum are added to argon, both electrical and thermal conduction increases at temperatures below approximately $15000 \mathrm{~K}$. The ratio of $\sigma / k$ changes little for temperatures between $10000 \mathrm{~K}$ and $15000 \mathrm{~K}$, As has previously been shown(15), the arc temperature is dependent to a first approximation on the ratio of $\sigma 7 \mathrm{k}$. It is not suprising, therefore, to note a small effect of aluminum on the arc configuration at this current leve1. At lower currents, the peak arc temperature is lower. In the low-temperature region, there are gross changes in the transport properties of the aluminum-argon gas mixtures which results in significant changes in the temperature and current density distributions between the pure argon arc and an arc containing aluminum additions. Such effects are shown in Figures 25 and 26. Although the total current necessary to yield such low temperatures is relatively small, the same effect could be expected at higher arc currents but with a higher content of aluminum vapor present in the gas. Recent spectroscopic measurements of the arc have detected the presence of base metal vapor in the anode region of an arc discharge $(3,15)$. Additional study is necessary to determine the rate of base metal vaporization from the weldment and the concentration of minor elements throughout the arc region in order to accurately predict the effects of such element additions to the welding arc. 


\section{Analysis of Temperature Distribution Measurements}

a) Data of Gick, Quigley and Richards

The spectroscopic measurements of the welding arc performed at the Bettis Laboratory were limited to determining the peak temperature along the arc ax1s(15). Using an electrostatic probe technique, Gick et al(5) were able to map the entire axial and radial temperature distribution of a 100 A GTAW arc. Their results are shown in Figure 27. The radial temperature distribution $4 \mathrm{~mm}$ below the cathode is shown in Figure 28 along with the calculated temperature distribution for a $100 \mathrm{~A}$ argon arc obtained from the program COLMN. Assuming the peak temperature to be correct, the rapid decrease in the radial temperature is inconsistent with a $100 \mathrm{~A}$ current flow. The inconsistency is demonstrated by integrating the current density distribution $f(r)$ over an entire arc plane $4 \mathrm{~mm}$ below the cathode to obtain the total current I. This is calculated as follows:

$$
I=\int_{0}^{\infty} 2 \pi r f(r) d r
$$

where the current density $j(r)$ is given by

$$
f(r)=\sigma(r) E .
$$

The radial dependence of $\sigma(x)$ is readily obtained from the temperature dependence of $\sigma$ given in Figure 4. Changing the integral to a summation over discrete intervals $\Delta \mathbf{r}_{1}$

$$
I=\sum_{r_{i}} 2 \pi r_{i} \sigma\left(r_{i}\right) E \Delta r_{1}
$$

The summation is taken over intervals of $\Delta r_{i}=1.0 \mathrm{~mm}$. Using the values of electrical conductivity given in $\mathrm{Figure} \mathrm{4,} \mathrm{and} \mathrm{an} \mathrm{average} \mathrm{electric} \mathrm{field}$ intensity of $8 \mathrm{~V} / \mathrm{cm}$ obtained experimentally (Figure 15), the resultant total 
are current is 25A. This is a factor of 4 smaller than the experimental 100 A which supposedly yielded the measured temperature distribution. Conversely if we assume the current to be $100 \mathrm{~A}$, an electric field strength of $33 \mathrm{~V} / \mathrm{cm}$ is necessary for consistency; this is a value much higher than any realistic estimate. Integrations over other planes reveal similar inconsistencies.

Repeating the above analysis at other 2 planes, the total plasma voltage (excluding the anode and cathode drop regions) may be found from the following relation

$$
v=\int_{0}^{h} E(z) d z
$$

where the limit of integration extends a distance $h$, from the cathode to anode. The calculations yield a total voltage drop of $38 \mathrm{~V}$. For an $8 \mathrm{~mm}$ arc gap, this implies an average electric field intensity of $48.5 \mathrm{~V} / \mathrm{cm}$. Such a value is contrary to experimental results. Thus, regardless of the limitations of the one-dimensional model, the experimental temperature distribution given by Gick et al is inconsistent with the transport properties of an argon arc. Since the measured average electric field $188 \mathrm{~V} / \mathrm{cm}$, one must conclude that the peak temperature measured by Gick 18 too small, or the radial temperature falloff is too rapid. These results have initiated further analyses of other experimental temperature data for welding arcs. In particular, the work of Evans and Tankin is reviewed in the next section.

b) Data of Evans and Tankin

Employing spectroscopic techniques, Evans and Tankin have deduced the radially and axially varying temperature distribution of a 250 A free burning argon arc(17): An arc length of $6 \mathrm{~mm}$ was used with various gas 
pressures. The results are reproduced in Figure 29. From these data, and employing the same methods previously described, the electric field intensity as a function of radial position has been determined for the $250 \mathrm{~A}$ arc at one atmosphere argon pressure.

The results shown in Figure 30 reveal a high electric field near the cathode which decreases as the anode 18 approached. The result is consistent.with what is to be expected for a pointed electrode. The total potential drop $V$, across the plasma region (excluding the anode and cathode drop regions), is found from the integral under the curve of Figure 30 to be $5.5 \mathrm{~V}$. Using this value, an average electric field $\bar{E}$ is determined as follows

$$
\overline{\mathrm{E}}=\frac{\Delta \mathrm{V}}{\Delta \mathrm{Z}}=\frac{5.5}{0.6}=9 \mathrm{~V} / \mathrm{cm}
$$

This is an excellent agreement with the $8 \mathrm{~V} / \mathrm{cm}$ result obtained for the 90-145A arcs described in Figure 15. The analysis can be reversed. Assuming an average electric field of $9 \mathrm{~V} / \mathrm{cm}$ the integrated current calculated from equation 22 will be $250 \mathrm{~A}$, in excellent agreement with the experiment at all planes. Since the total arc voltage for the 250 A arc described by Evans and Tankin is not given, a value of approximately $12 \mathrm{~V}$ is assumed. Assuming the anode and cathode drop to be approximately $6 \mathrm{~V}$, a reallstic plot of the potential as a function of distance from the cathode tip is shown in Figure 31.

IV. Summary and Conclusions

Welding development has progressed mainly as a result of extensive experimental effort with the theoretical justificetion playing a secondary role. But sophisticated technology and the advent of automation to welding techniques now require a better theoretical understanding of the basic physics 
of the welding arc. Because of the complexity of the arc discharge no complete theory exists which fully describes the arc in its entirety. Therefore, as a start, a one-dimensional model of the arc which treats heat generation by the Joule effect and heat $108 s$ by thermal conduction and radiation has been used to study the effects of the transport properties of various gases on the input energy distributions to the weldment.

In particular, small additions of metallic vapor such as aluminum is shown to significantly perturb the radial temperature distribution of the welding arc. As a result, the current density distribution which is directly related to the temperature dependent electrical conductivity 18 changed, and the input energy distribution to the weldment will be perturbed. This results in variations in weld penetration. Any minute amount of low Ionization potential element addition to the welding gas can cause significant changes in the configuration of the weld bead.

Welding arc shielding gases containing mixtures of argon and helium which are commonly used in the GTAW process have also been studied. The analytical model reveals that extremely small $(<1 \%)$ additions of argon gas can significantly perturb a pure helium discharge, while small additions of helium to an argon discharge has little effect on the arc configurations. The greater energy input associated with the helium welding arc as compared to an argon arc at the same current does not result from a "hotter" temperature arc as commonly belleved. Experimental measurements of the electric flelds and analysis of the potential drop associated with each gas discharge show that the greater energy of helium can be attributed to a larger anode drop potential relative to that of argon arce. 
The one-dimensional are model has clearly shown that radiation $108 \mathrm{ses}$ for a 100A arc cannot be considered negligible as has been reported by other investigators. Indeed, radiation losses are an important factor in the energy conservation equation for an argon arc with temperatures greater than $10000 \mathrm{~K}$. Radiation losses reduce the peak temperature along the arc axis and broaden the temperature distribution.

Some of the limited experimental temperature distribution data that have been reported for welding arcs have been analyzed. Using reasonable estimates of the electric field strength deduced from experimental data and temperature dependent electrical conductivity data for argon gas, the current density distribution in an arc can be inferred from reported temperature distributions. With such an analysis, recently reported experimental data for temperature distributions in a $100 \mathrm{~A}$ welding arc are shown to be fincorrect. The results of the same type analysis applied to results reported for $250 \mathrm{~A}$ welding arcs are in excellent agreement with the test data.

These evaluations of experimental arc studies coupled with the onedimensional arc model help to explain the effects of various gases used for welding, improve our understanding of the basic physics of the welding arc, and provide a stepping stone for a more elaborate model in the future which can be applied to help optimize welding parameters. Acknowledgement

I would like to express my appreciation to Dr. E. Friedman for his many helpful suggestions and criticisms during the course of this study, and to Dr. R. W. Liebermann for calculating and making available the transport properties of inixed gases. 
REFERENCES

1. A. C. Nunes Jr., "Arc Welding Origins," Weld J. 55, July 1976.

2. E. Friedman and S. S. Glickstein, "An Investigation of the Thermal Response of Stationary Gas Tungsten Arc We1ds," Weld Jee Res, Supp. 55, 408-8, December 1976.'

3. W. S. Bennett and G. S. Mil1s, "GTA Weldability Studies on High Manganese Stainless Steel," Welding J.e Res, Supp. 53, 548-8, December 1974.

4. S. S. Glickstein and W. Yeniscavich, "A Review of Minor Element Effects on the Welding Arc and Weld Penetration," WRC Bulletin 226, May 1977.

5. A. B. F. Gick, M. B. C. Quigley, and P. H. Richards, "The Use of Electrostatic Probes to Measure the Temperature Profiles of Welding Arc8," J. Phys. D: App1. Phys. 6, 1941-1949, 1973.

6. J. P. Schafer, "The Influence of Radiation on Arc Constriction in the Anode Region," M. S. Thesis, University of Minnesota September 1972.

7. E. Pfender and J. Schafer, "The Influence of Radiation on Arc Constriction in the Anode Region," AIAA/ASME 1974 Thermophysics and Heat Transfer Conference, ASME Paper No. 74-HT-34, July 1974.

8. G. Ecker, "hodern Developments of the Theory of Electrode Regions of An Electrical Arc," Translated from Teplofizika Vysokikh Temperatur, 11, No. 4, 865-870, July-August, 1973.

9. T. S. Chou, "Anode Contraction Mechanism of High Intensity Arcs," Ph.D. Thesis, University of Minnesota, 1971.

10. S. S. Glickstein, E. Friedman and W. Yeniscavich, "An Invesgiation of Alloy 600 Welding Parameters," Weld. J.e Res. Supp. 54, 113-8, April 1975.

11. "Welding Handbook," 6th Ed, Chap. 3, A, L. Phlllips, Ed., American Weld. Soc., N.Y. N.Y. 1968.

12. R. W. Liebermann and C. L. Chen," "Thermodynamic and Transport Properties of $\mathrm{SF}_{6}$ Gas," Westinghouse Res. Lab. Report 77-1C64-ARCPL-P3 May 1977.

13. Max. F, Hoyaux, "Arc Physics," Springe-Ver lag, New York, 1968.

14. D. L. Evans and R. S. Tankin, "Measurement of Emission and Absorption Radiation by an Argon Plasma," Physics of Fluids 10, No. 6, June 1967.

15. S. S. Glickstein, "Temperature Measurements in a Free Burning Arc," Weld Journal, 55, Res. Supp 1., 222-8, August 1976. 
16. H. N. O1sen, "Determination of Properties of an Optically Thin Argon Plasma," Temperature, Vol. III, Part 1, Reinhold Pub. Co., N.Y., 1962.

17. D. L. Evans and R. S. Tankin, "Experimental Measurements of the Emission and Absorption of Radiation by an Argon Plasma," Aerospace Research Lab., ARL 67-0157, July 1967.

18. P. A. Schoeck "An Investigation of the Anode Energy Balance of High Intensity Arcs in Argon," in "Modern Developments in Heat Transfer," Warren Ibele, Ed., P. 353-478, Academic Press, New York and London, 1963.

19. M. B. C. Quigley, P. H. Richards, D. T. Swift-Hook, and A. E. F. Gick, "Heat Flow to the Workpiece from a TIG Welding Arc," J. Phys, D,: Appl, Phys. 6, 1973.

20. T. F. Chase, Jr. "The Effect of Anode Composition on Tungsten Arc Characteristics," Ph.D. Thesis, Rensselaer Polytechnic Institute, 1970.

21. J. C. Metcalfe and M. B. C. Quigley, "Arc Pool Instability in GTA Welding," Welding J., Res. Supp. 56; 133-S, May 1977

22. H. W. Drawin and P. Felenbolt, "Data for Plasmas in Local Thermodynamic Equilibrium," Gauther-Villars, Paris, 1965.

23. W. L. Wiese, M. W. Smith and B. M. Miles, "Atomic Transition Probabilities," Volume II, NSRDS-NBS 22, October 1969. 


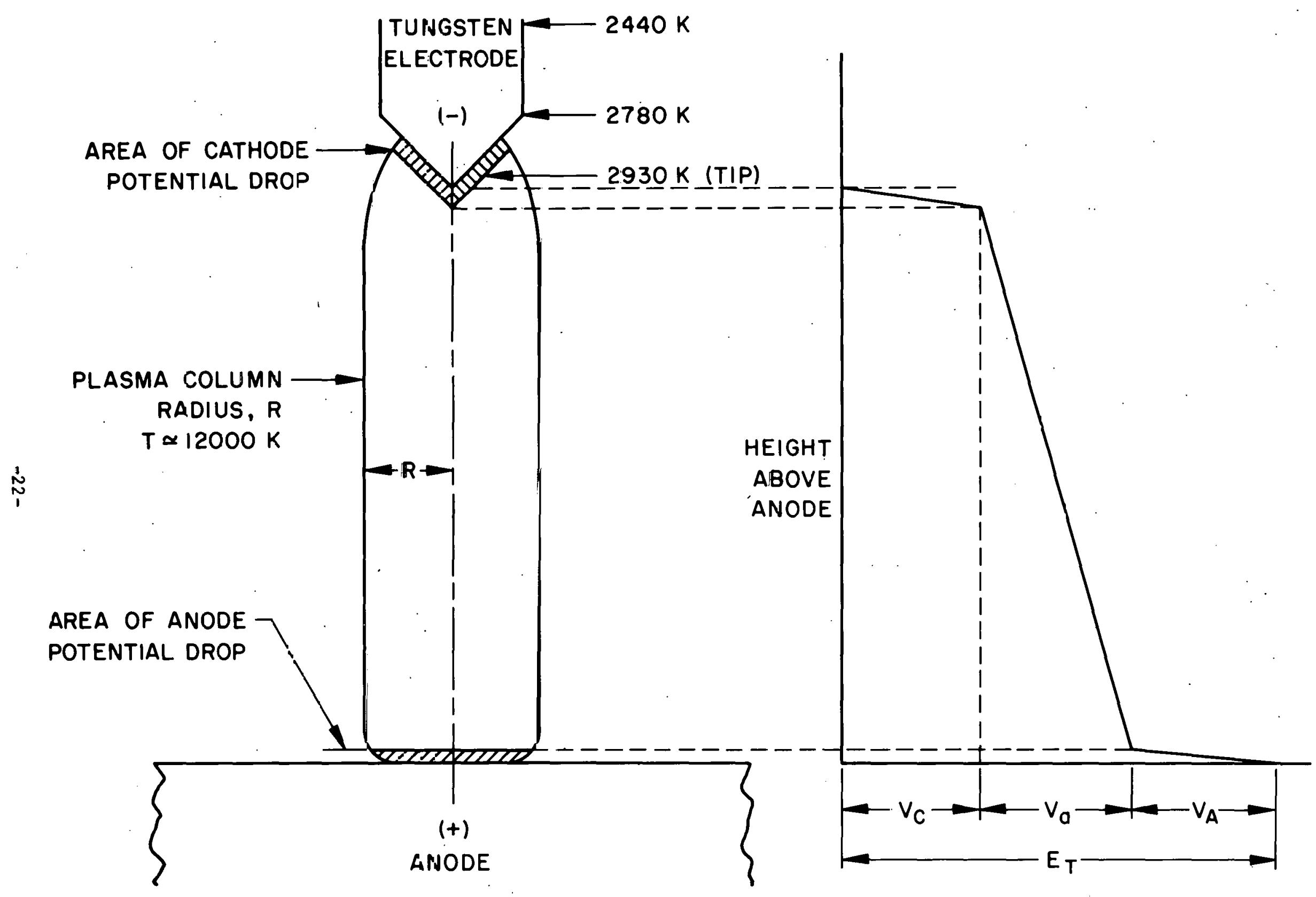

FIGURE I. TYPICAL VOLTAGE N'STRIBUTION OF A GAS TUNGSTEN ARr 
MEASURED VOLTAGE VS ARC GAP

FOR A HELIUM-ARGON GAS MIXTURE

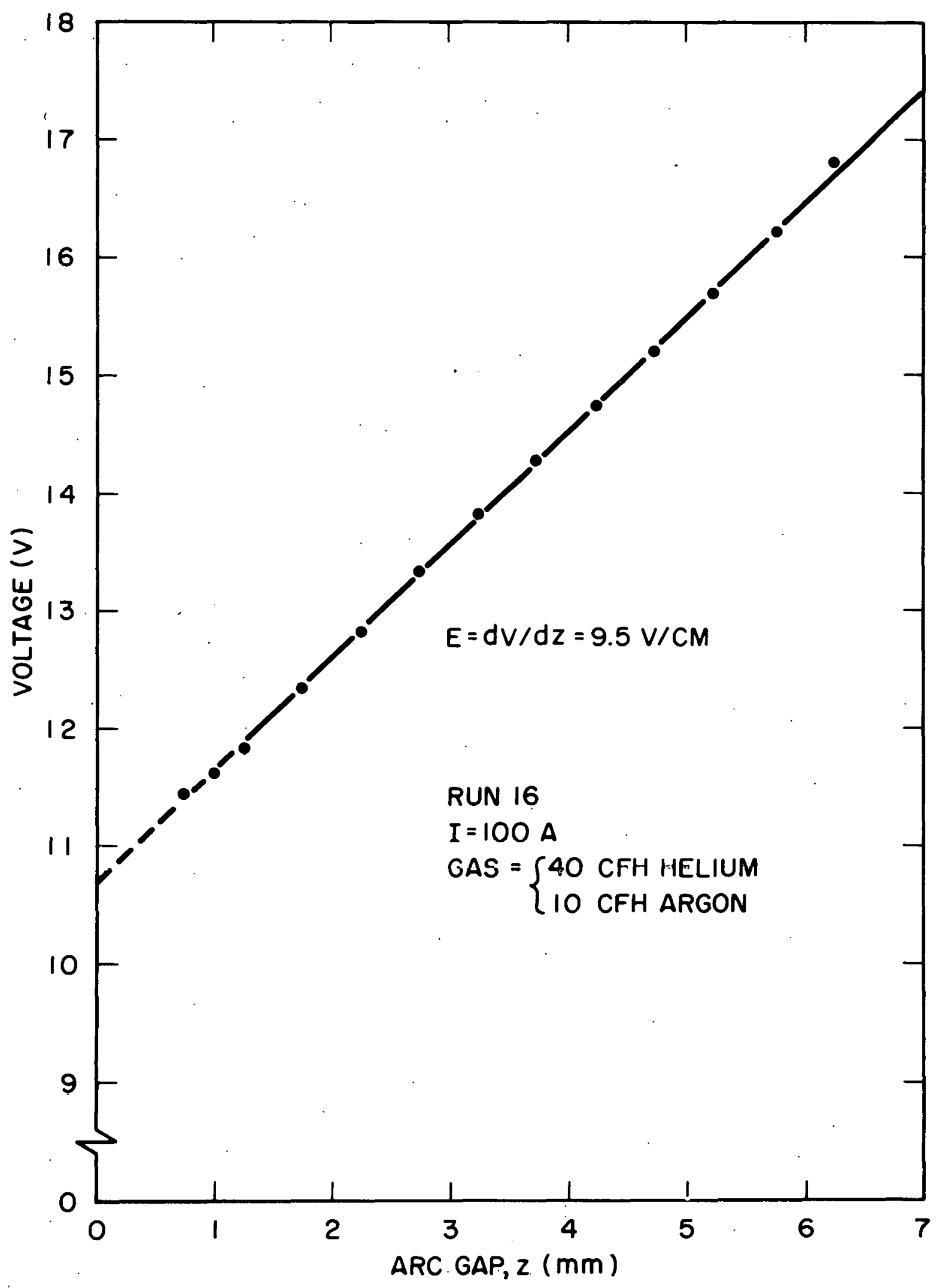

FIGURE 2 
ELECTRICAL CHARACTERISTICS FOR ARCS OF VARYING MIXTURE OF HELIUM AND ARGON GAS

$$
I=100 \mathrm{~A}
$$

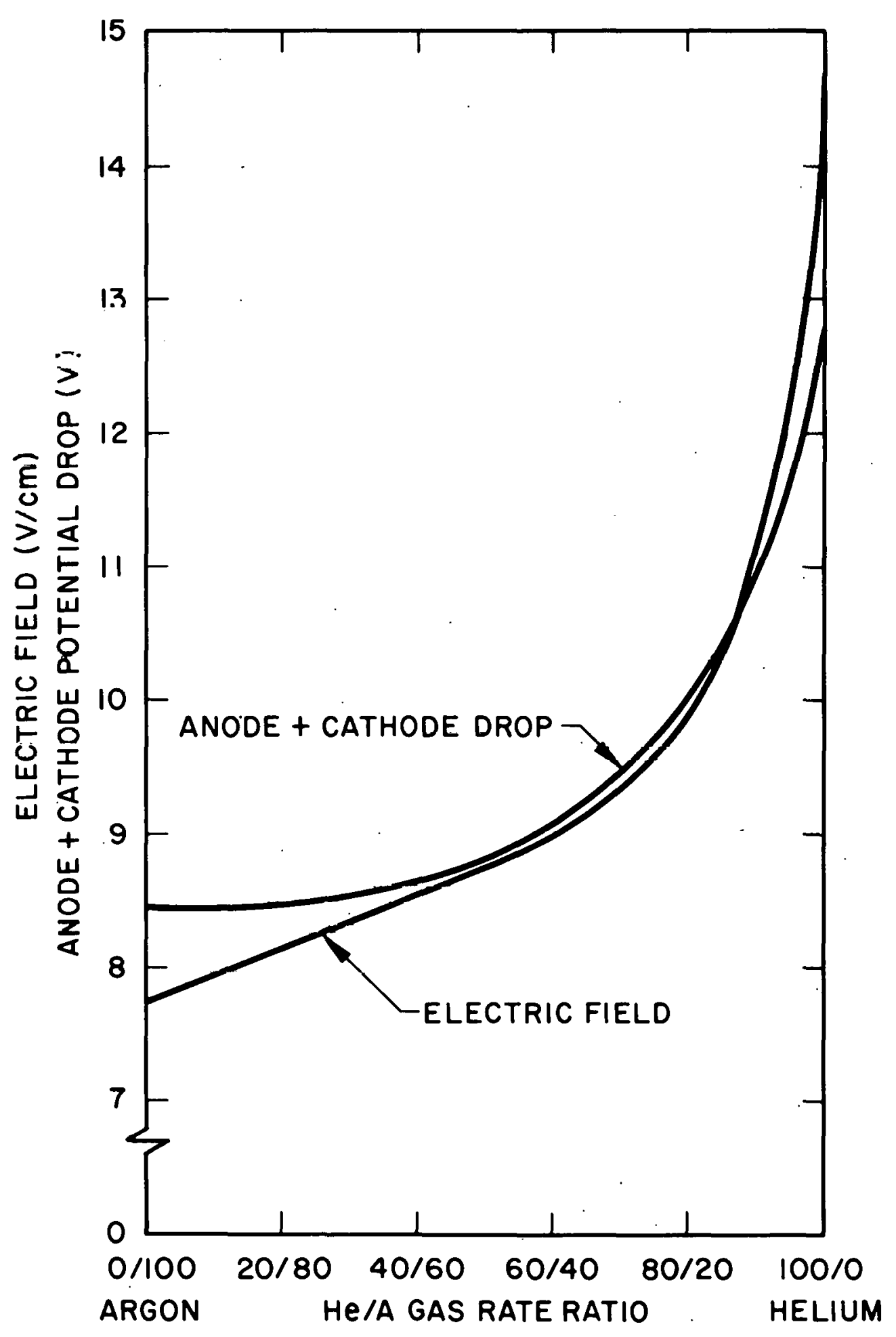

FIGURE 3

$-24-$ 


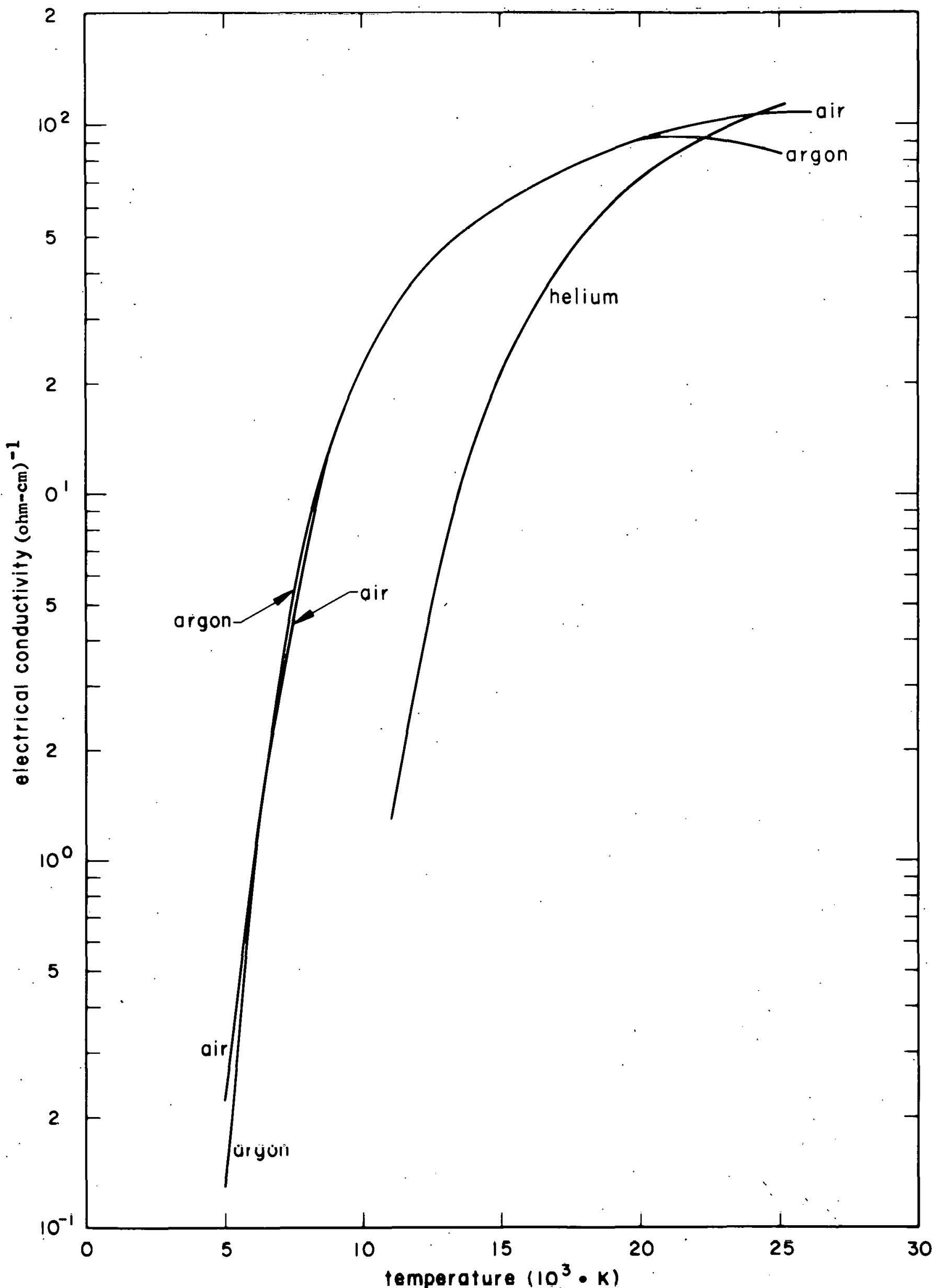

FIGURE 4 - Electrical conductivity of helium, argon and air as a function of temperature. $-25=$ 


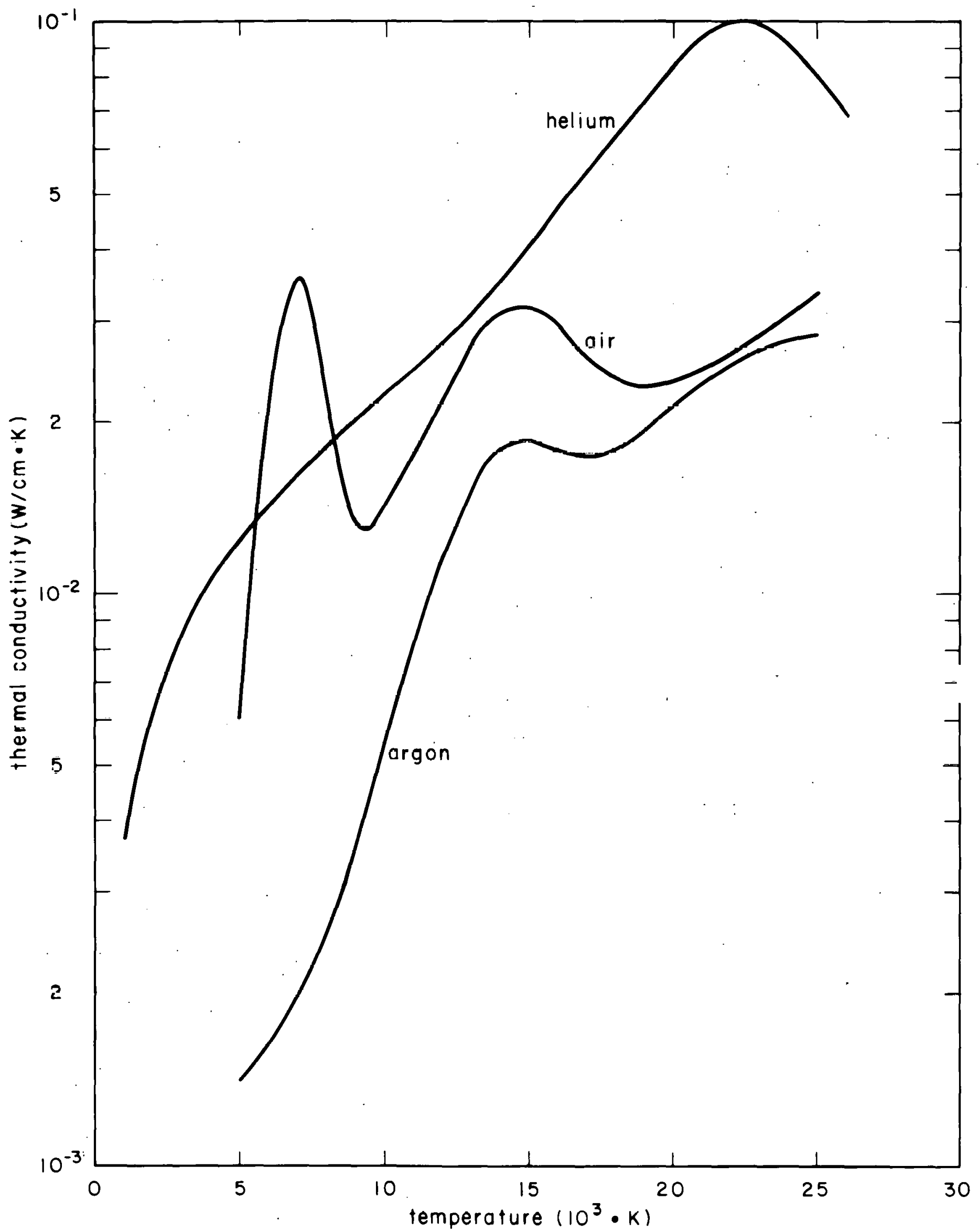

FIGURE 5, - Thermal conductivity of helium and argon and air as a function of temper: 


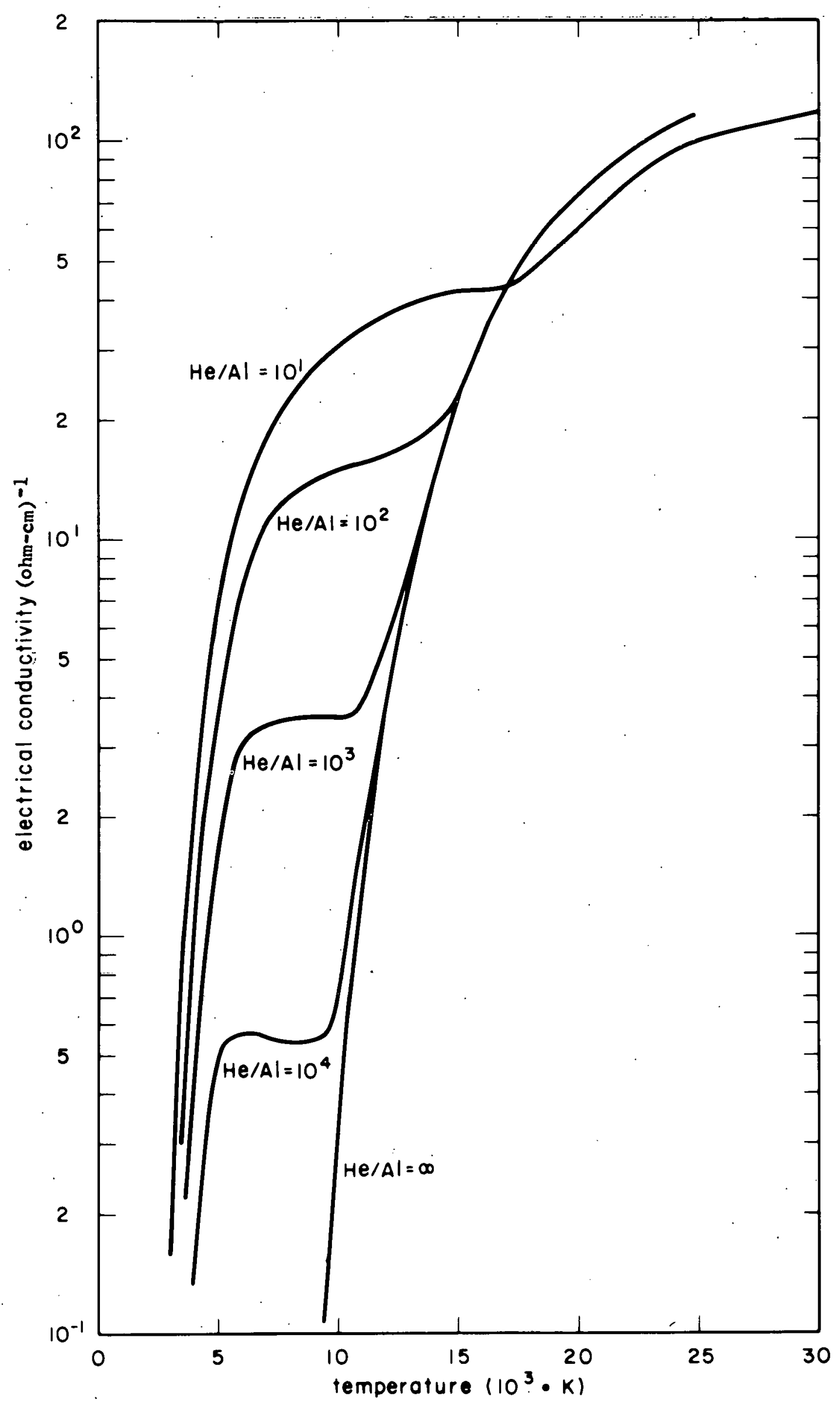

FIGURE 6. Electrical conductivity of HeAl gas mixtures: as a function of temperature.

$-27-$ 


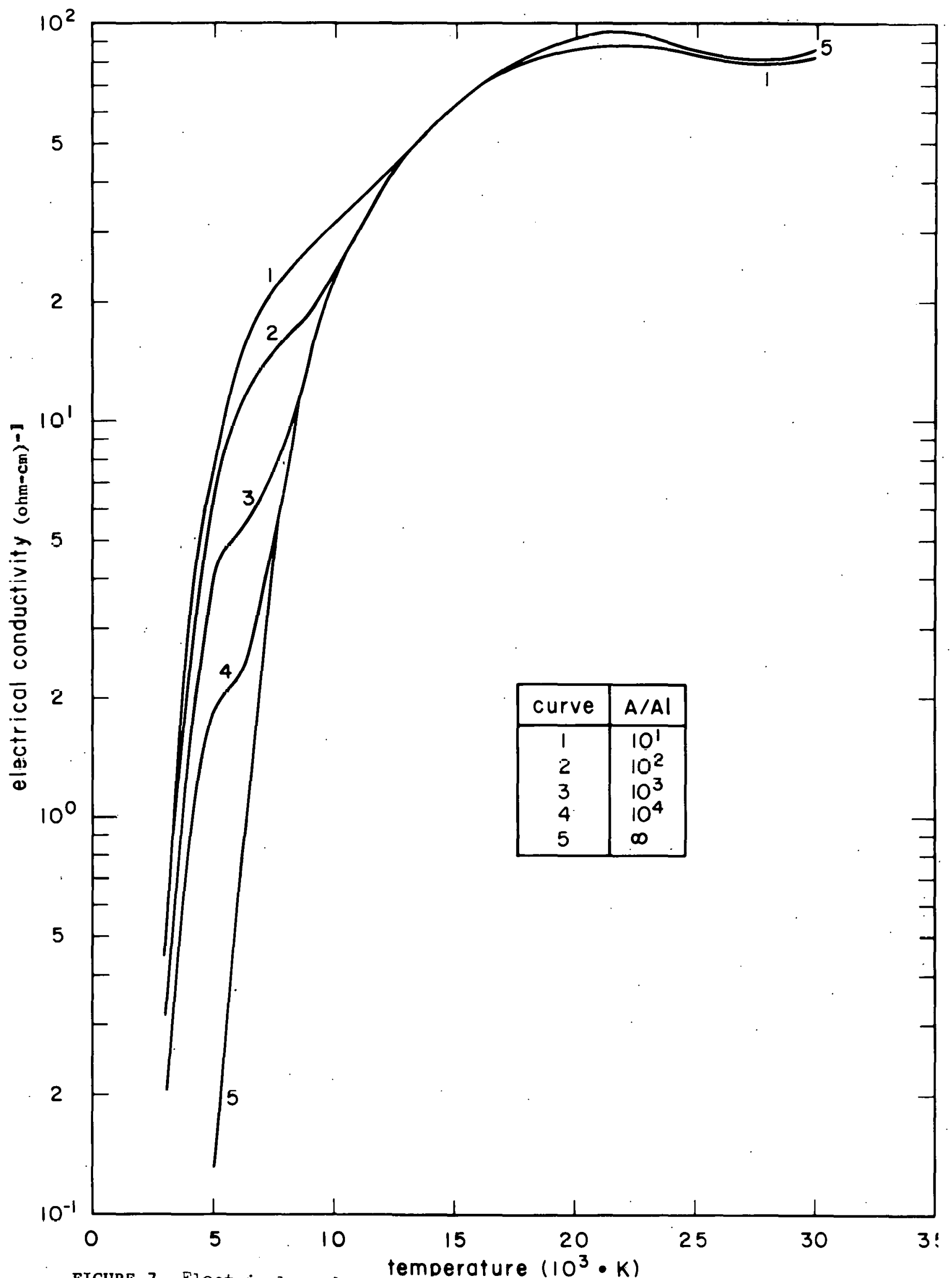

FIGURE 7. Electrical conductivity of $\mathrm{A}-\mathrm{Al}$ gas mixtures as a function of temperature. 


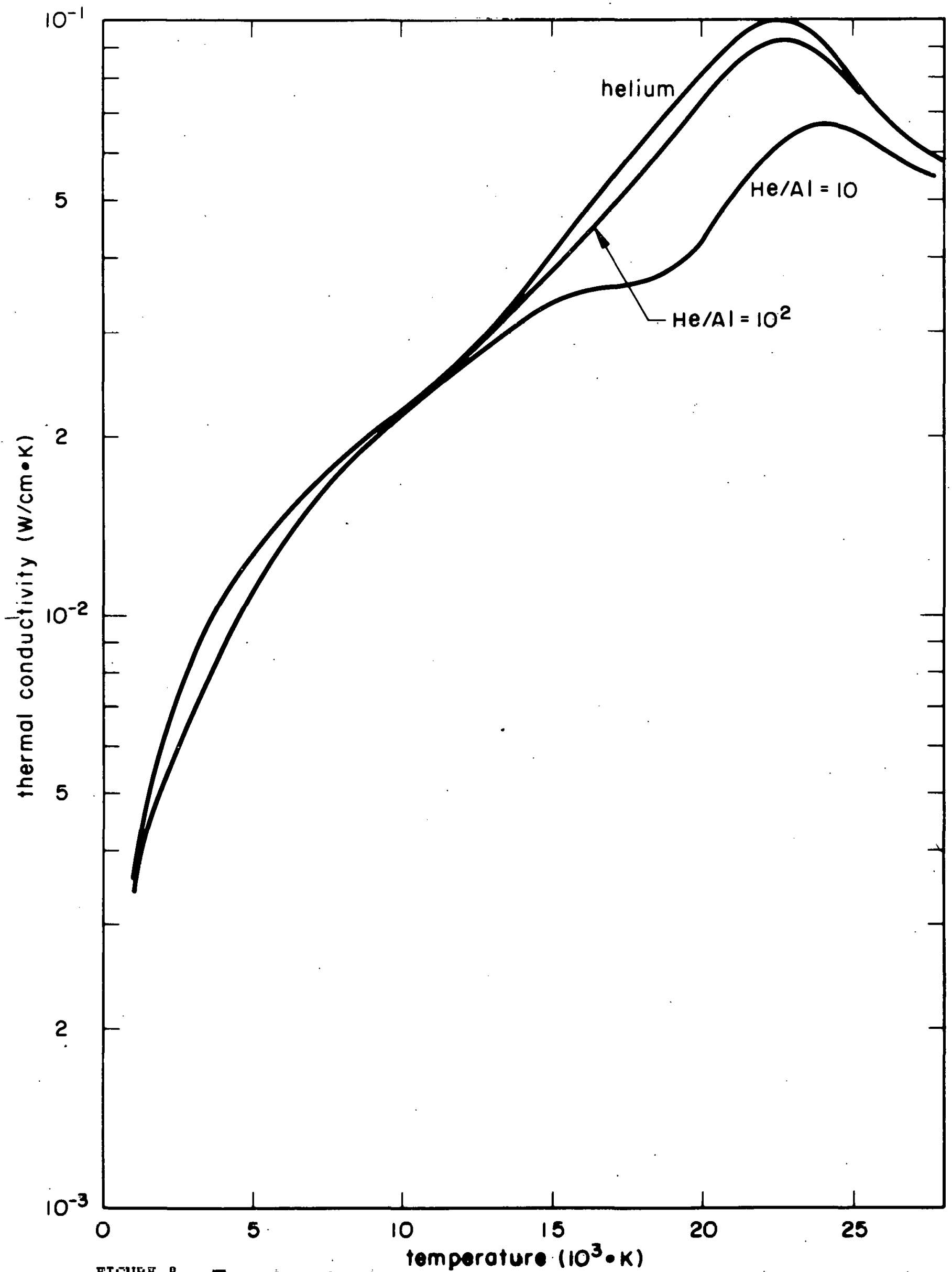

FIGUKE 8 Thermal conductivity of He-Al gas mixtures as a function of temperature. -29 - 


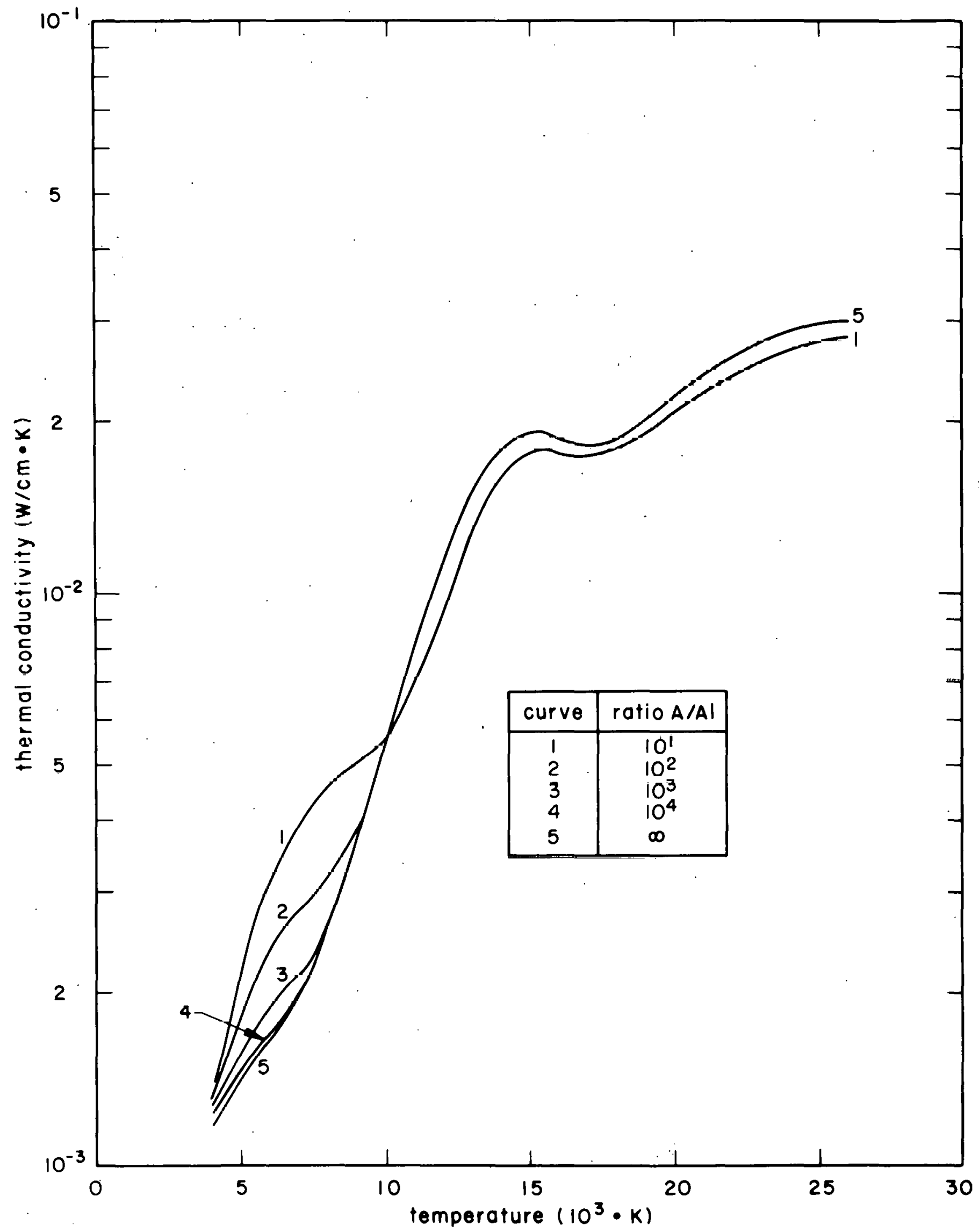

FIGURE 9 Thermal conductivity of A-Al gas mixtures as a function of temperature. 
ELECTRICAL CONOUCTIVITY OF HELIUM-ARGON GAS MIXTURES AS A FUNCTION OF TEMPERATURE

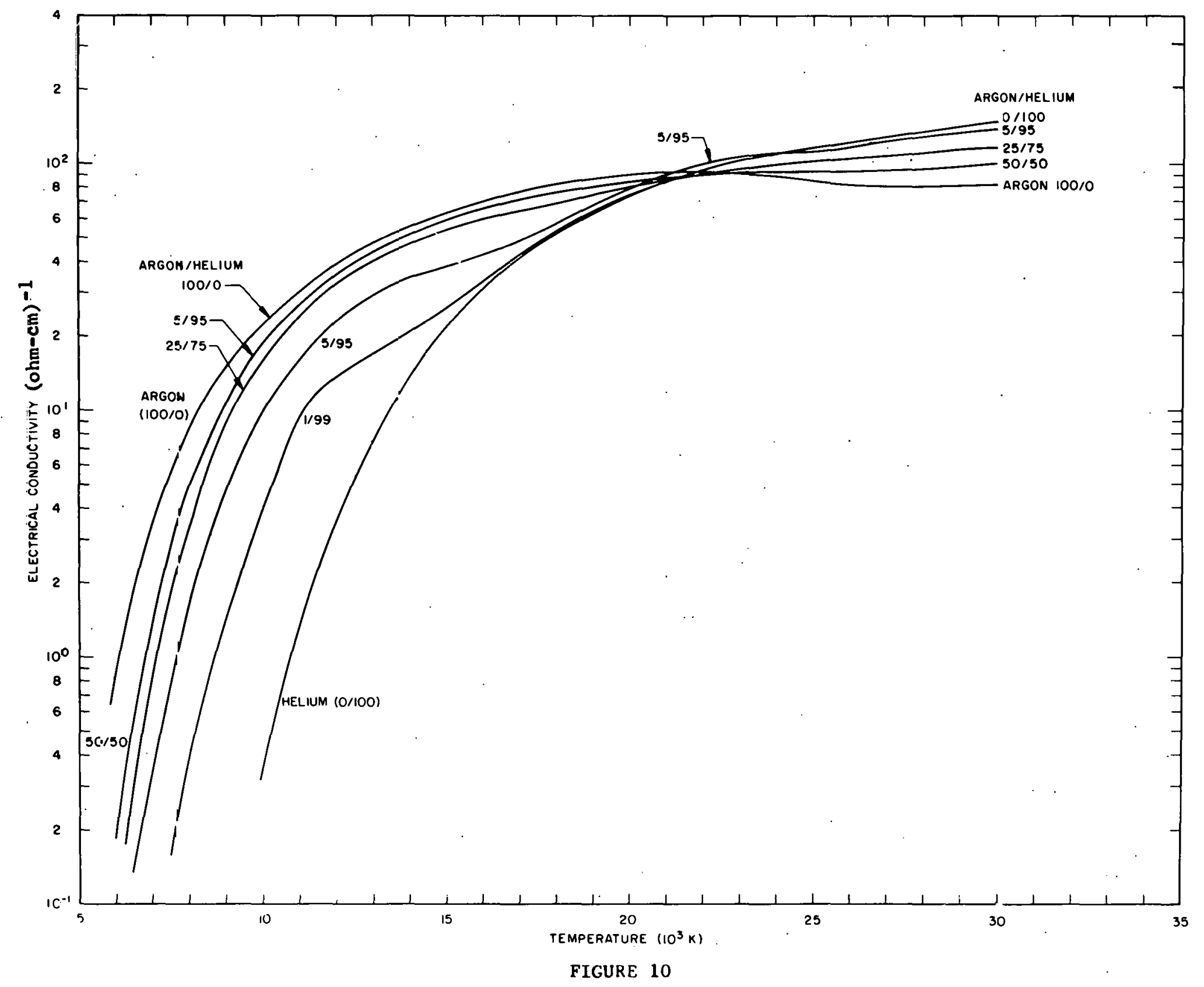

FIGURE 10

$-3.1-$ 
THERMAL CONOUCTIVITY OF HELIUN - ARGON GAS MIXTURES AS A FUNCTION JF TEMPERATURE

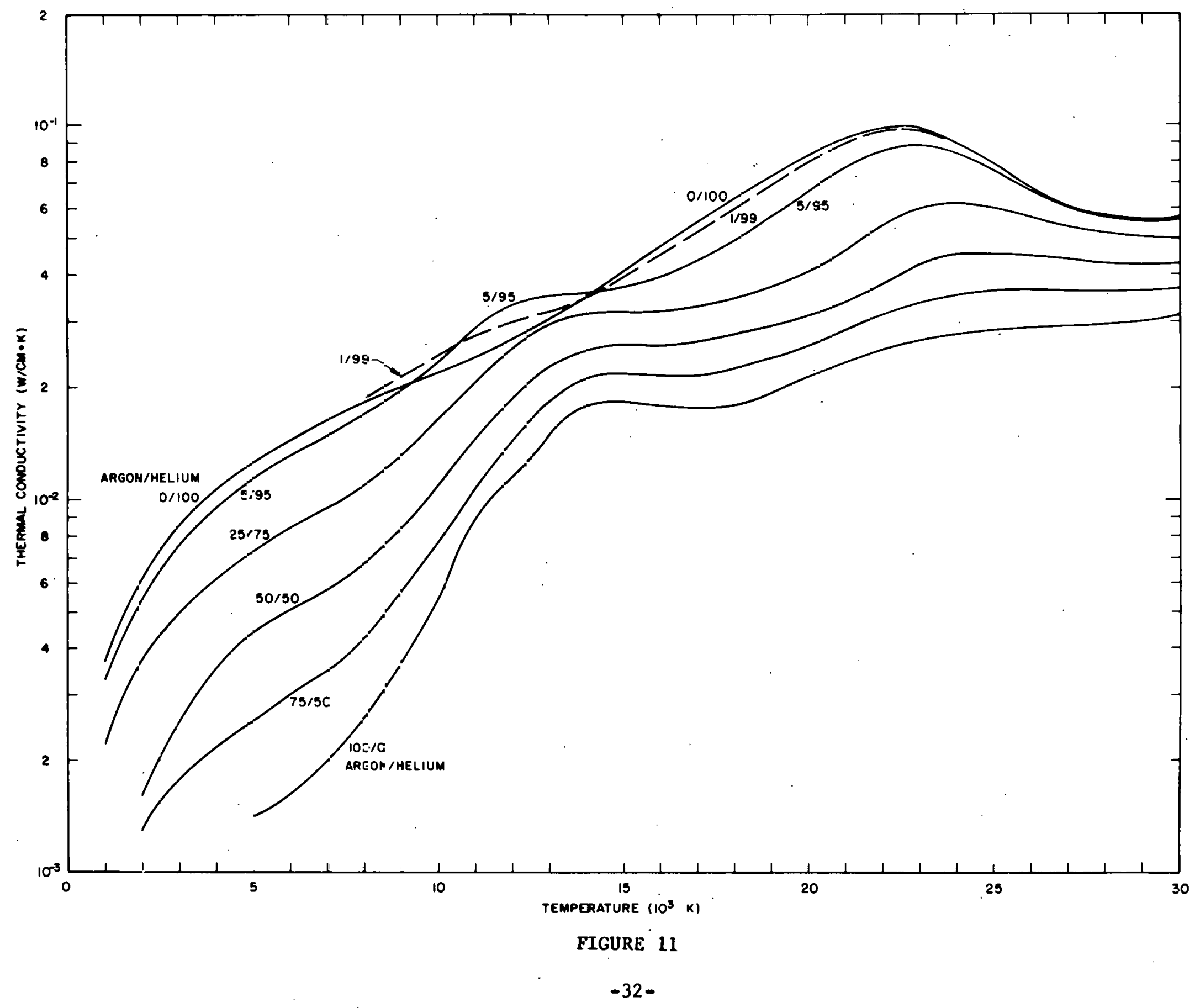




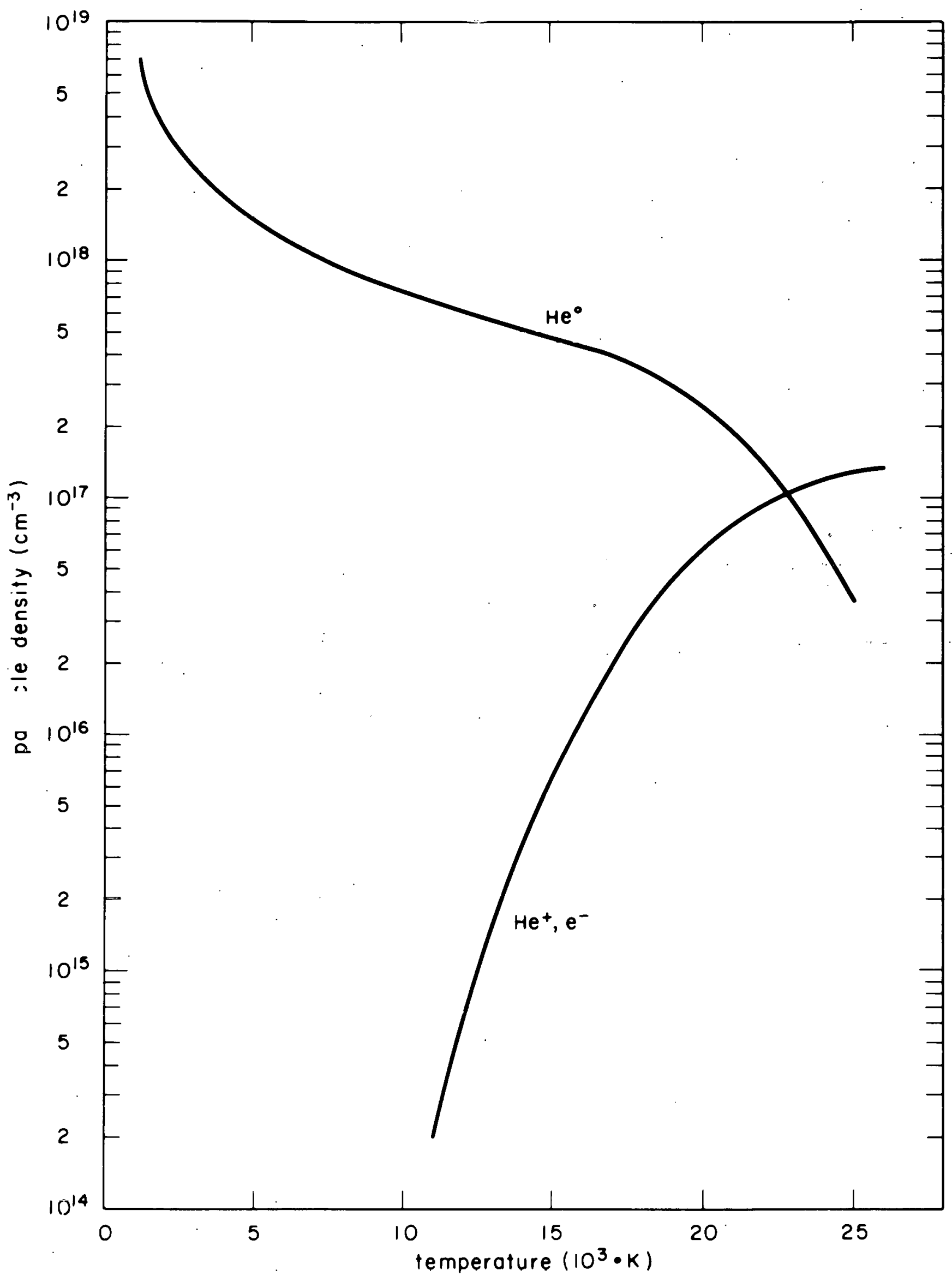

FIGURE 12a Electron, ion, and atom density as a function of temperature for helium gas. -33- 


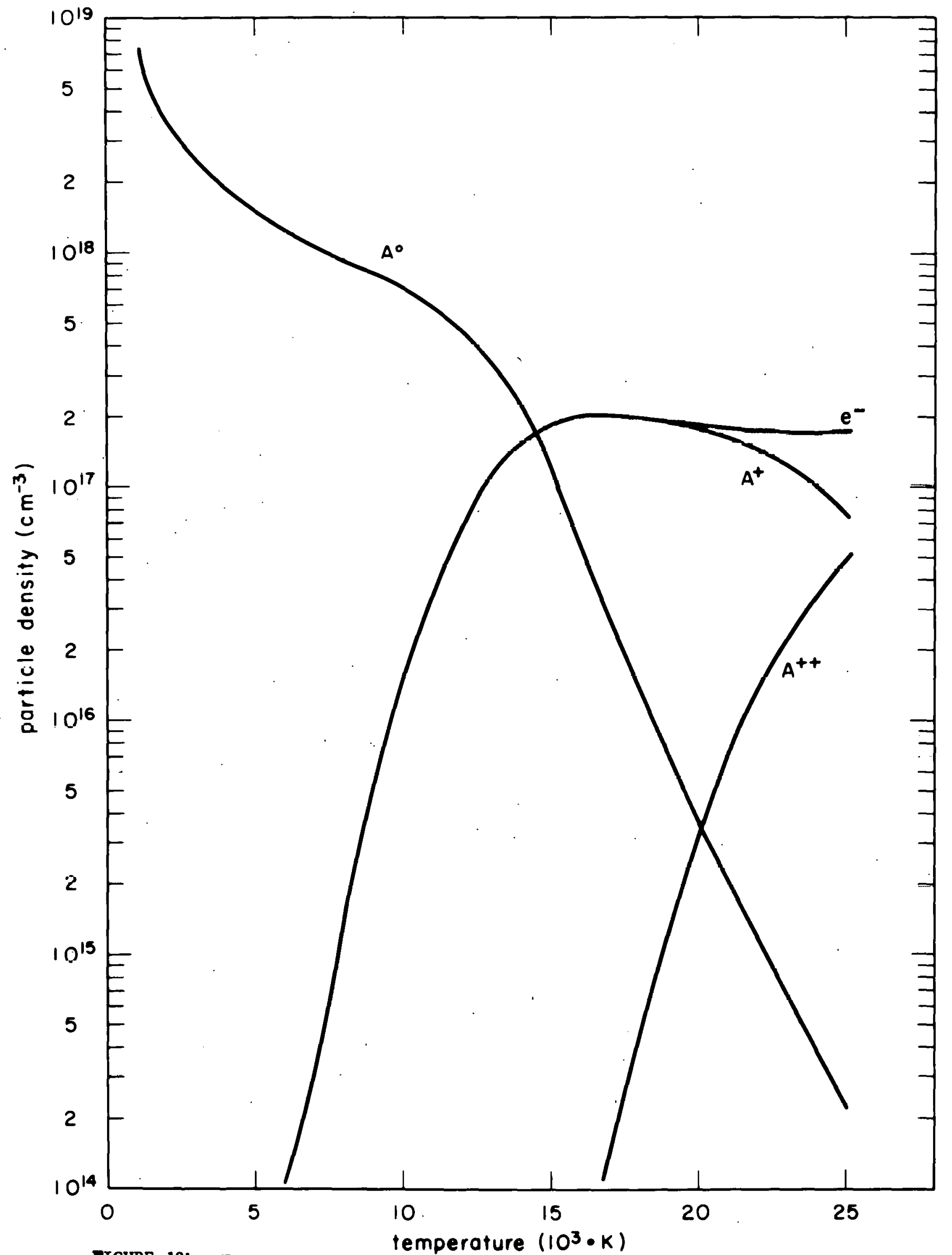

IIGURE 12b Electron, Ion and atom density as a function of temperature for argon gas. 


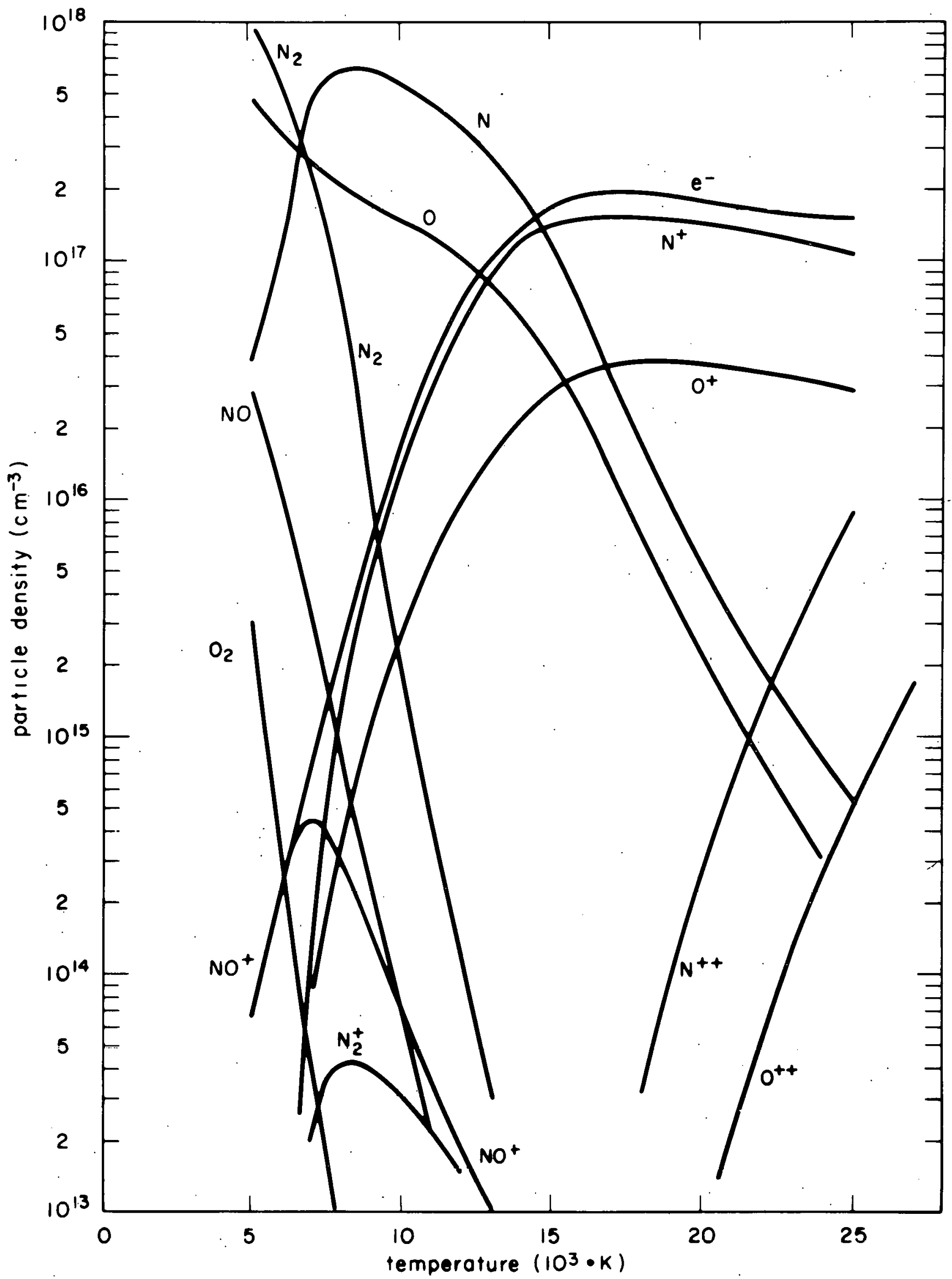

FIGURE 12c Electron, ion and atom density as a function of temperature for air containing $80 \%$ nitrogen and $20 \%$ oxy gen. 


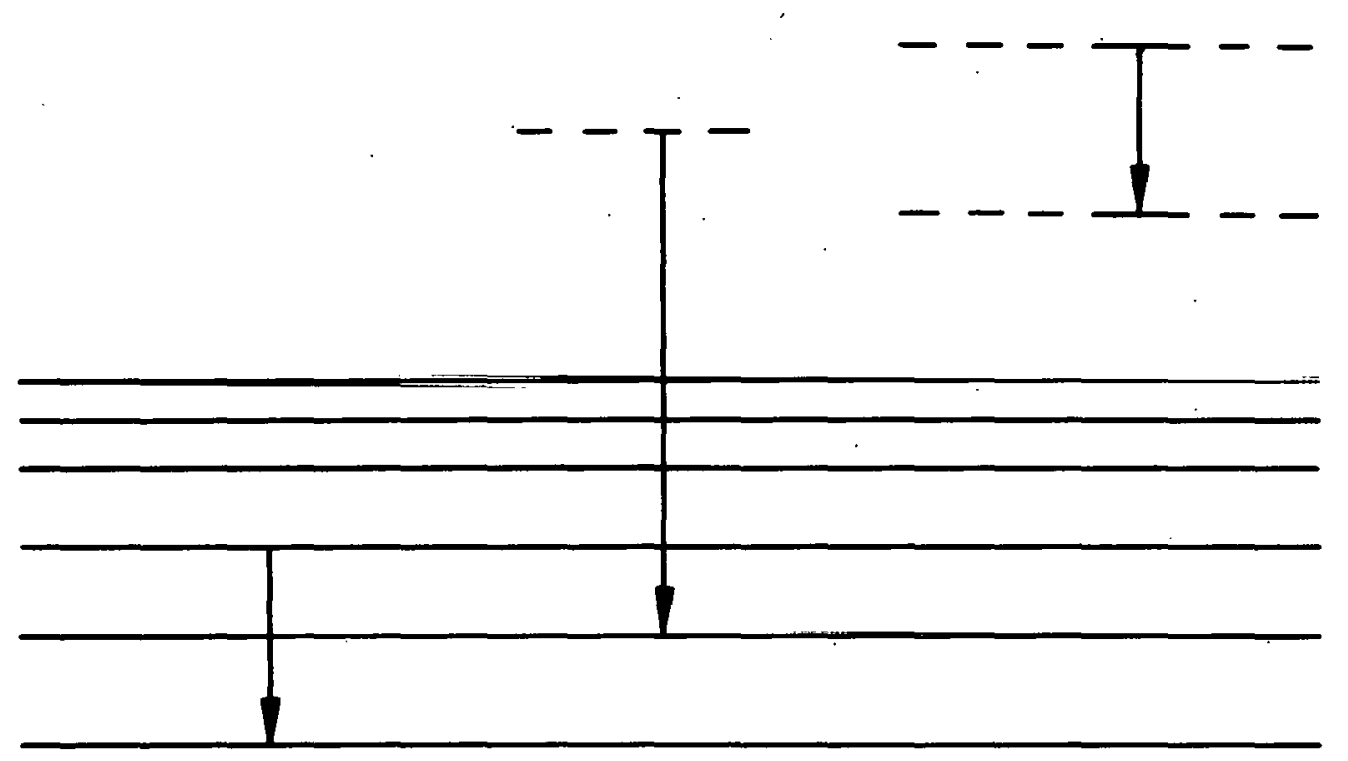

bound-bound

free-bound

$$
\begin{gathered}
\text { free-free } \\
\text { or "bremsstrahlung" }
\end{gathered}
$$

FIGURE 13 A reminder concerning quantic transitions in bound states and free states of an atom. 
ENERGY SOURCE TERM $\sigma E^{2}$ AS A FUNCTION OF TEMPERATURE FOR DIFFERENT ASSUMED

ELECTRIC FIELDS E

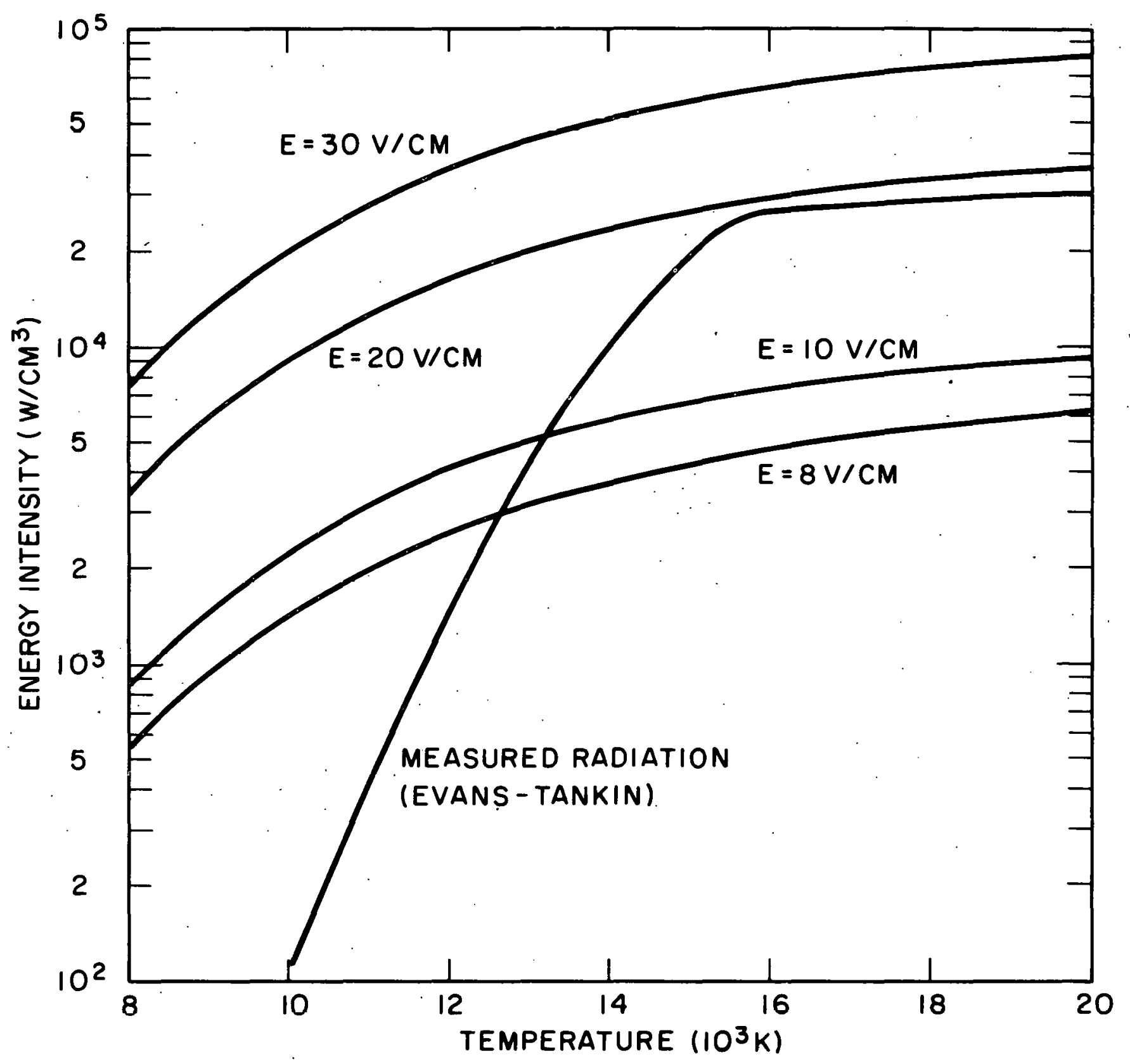

FIGURE 14 
VOLTAGE VS ARC GAP FOR ARGON ARC

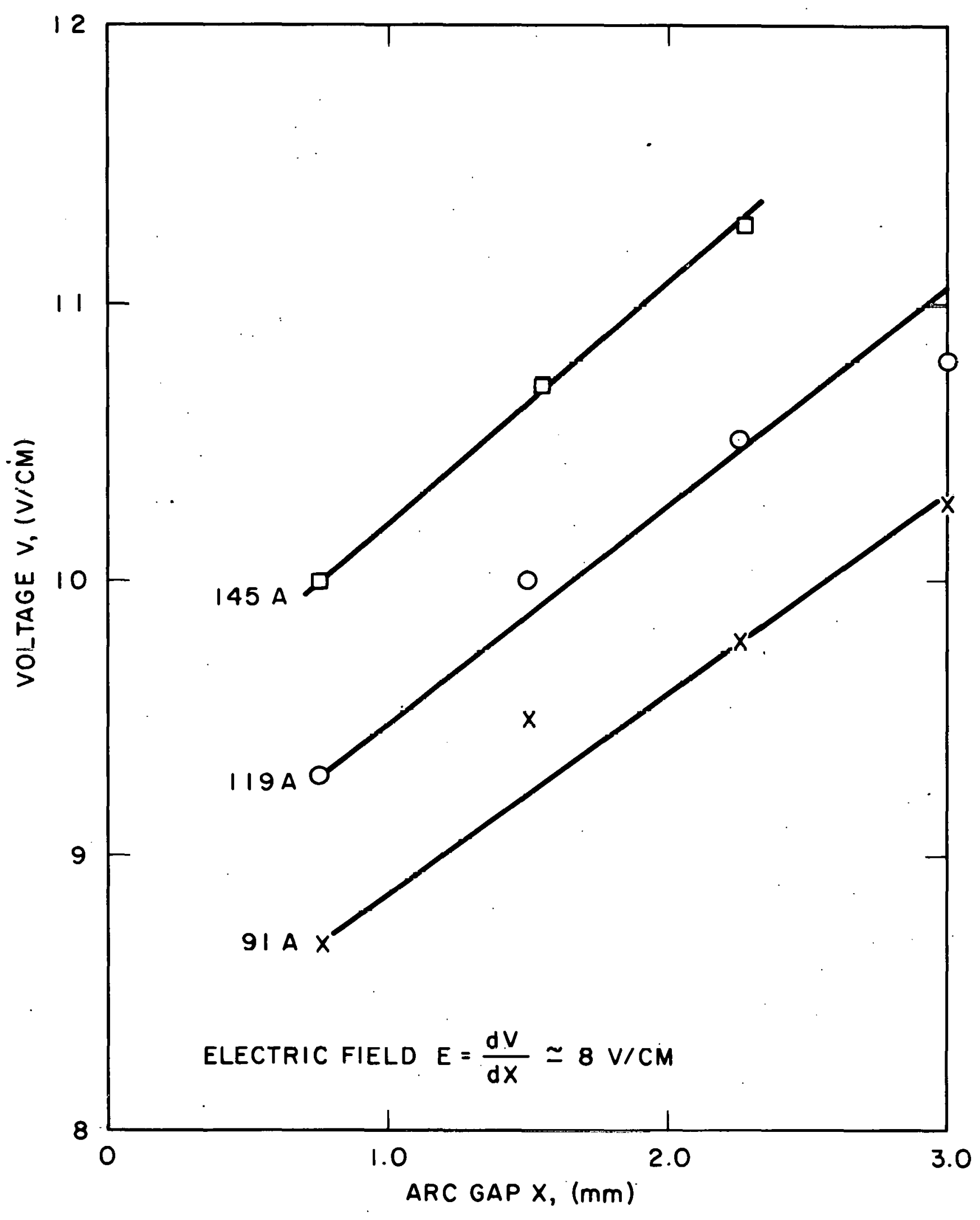

FIGURE 15 
CALCULATED RADIAL TEMPERATURE DISTRIBUTION WITH AND WITHOUT THE INCLUSION OF RADIATION EFFECTS

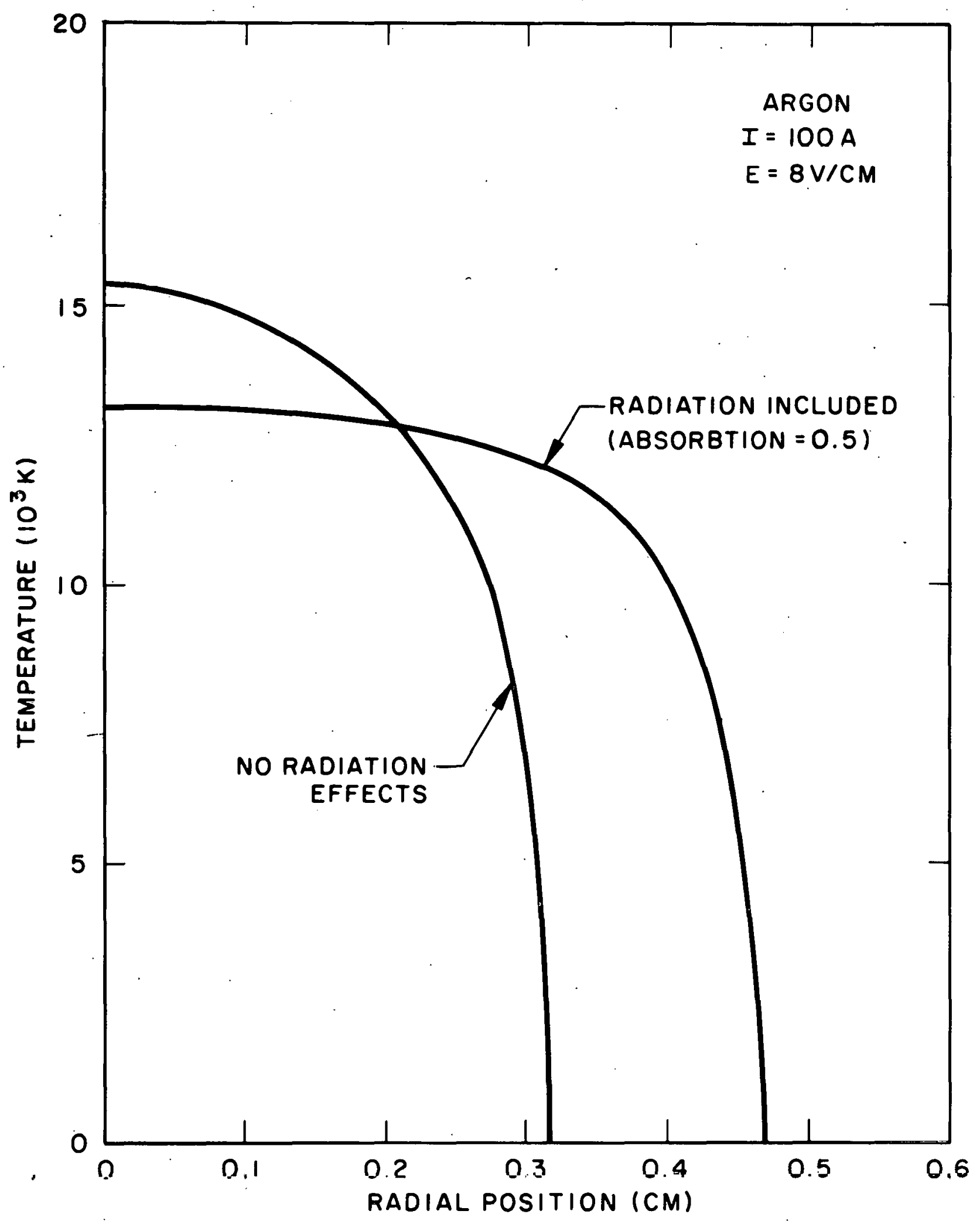

FIGURE 16 
CALCULATED RADIAL CURRENT DENSITY DISTRIBUTION WITH AND WITHOUT THE INCLUSION OF RADIATION EFFECTS

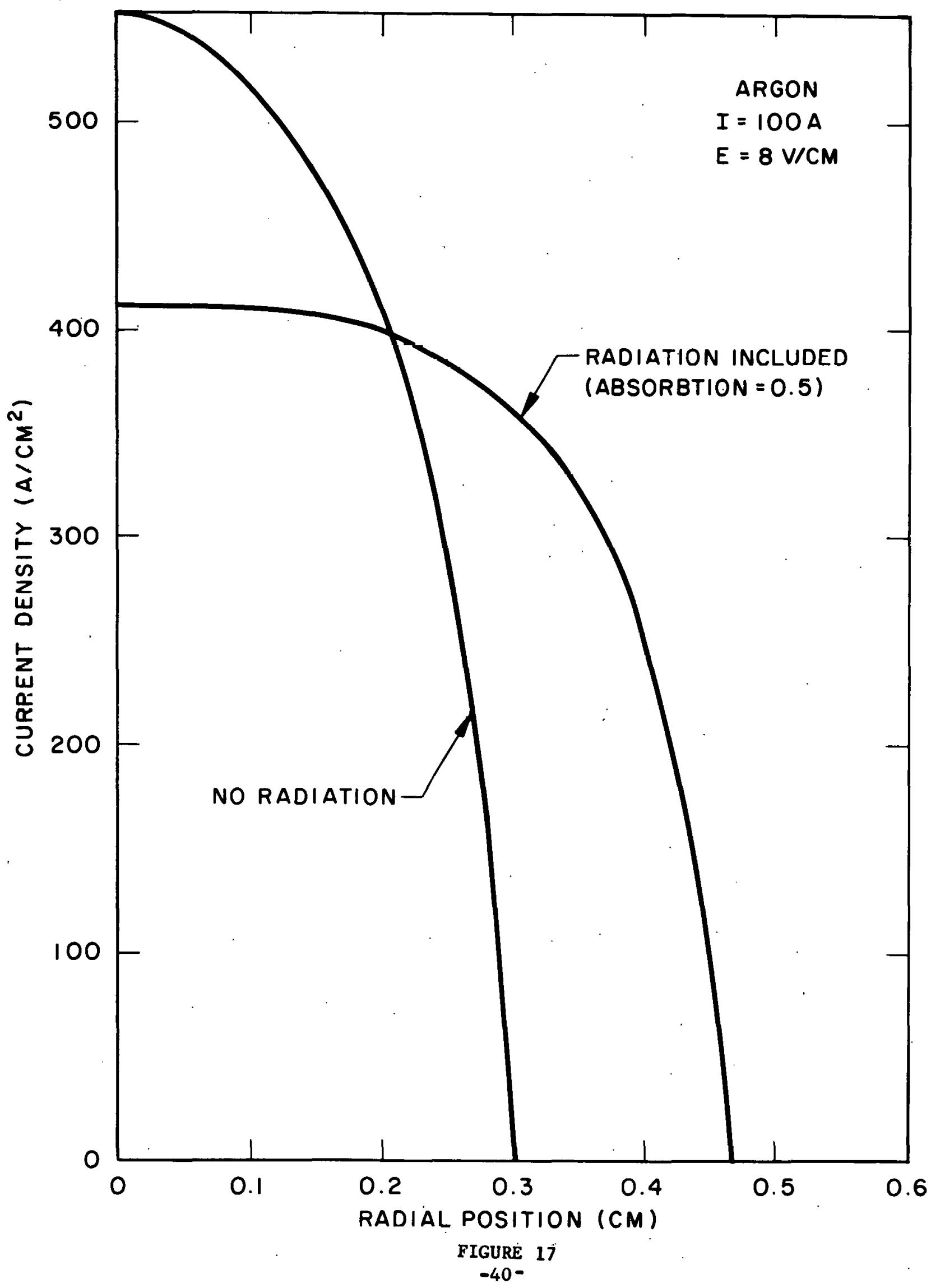


RADIAL TEMPERATURE DISTRIBUTION FOR PURE HELIUM AND ARGON ARCS

$I=100 \mathrm{~A}$

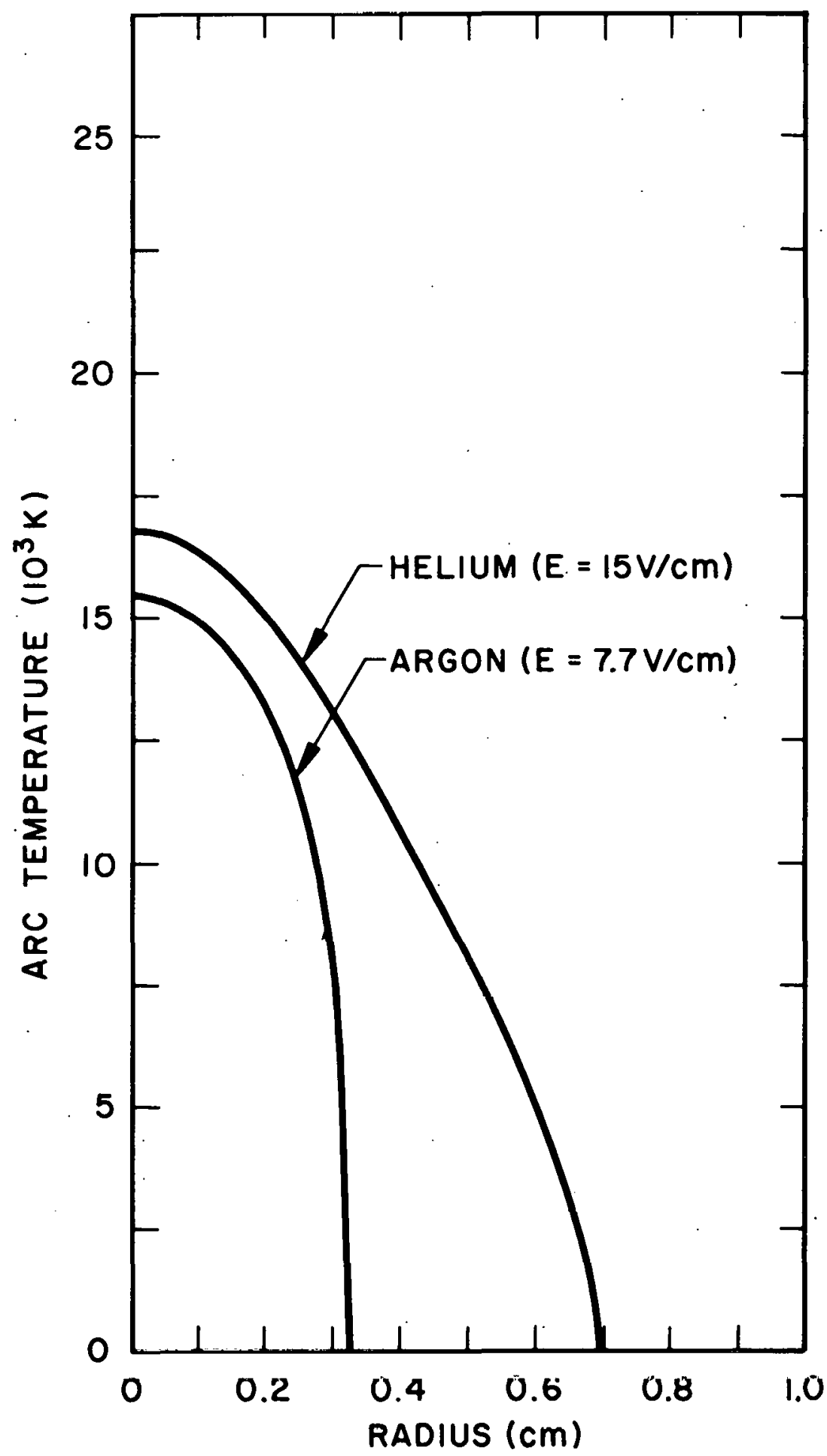

FIGURE 18 
RADIAL CURRENT DENSITY

DISTRIBUTION FOR PURE

HELIUM AND ARGON ARCS

$I=100 \mathrm{~A}$

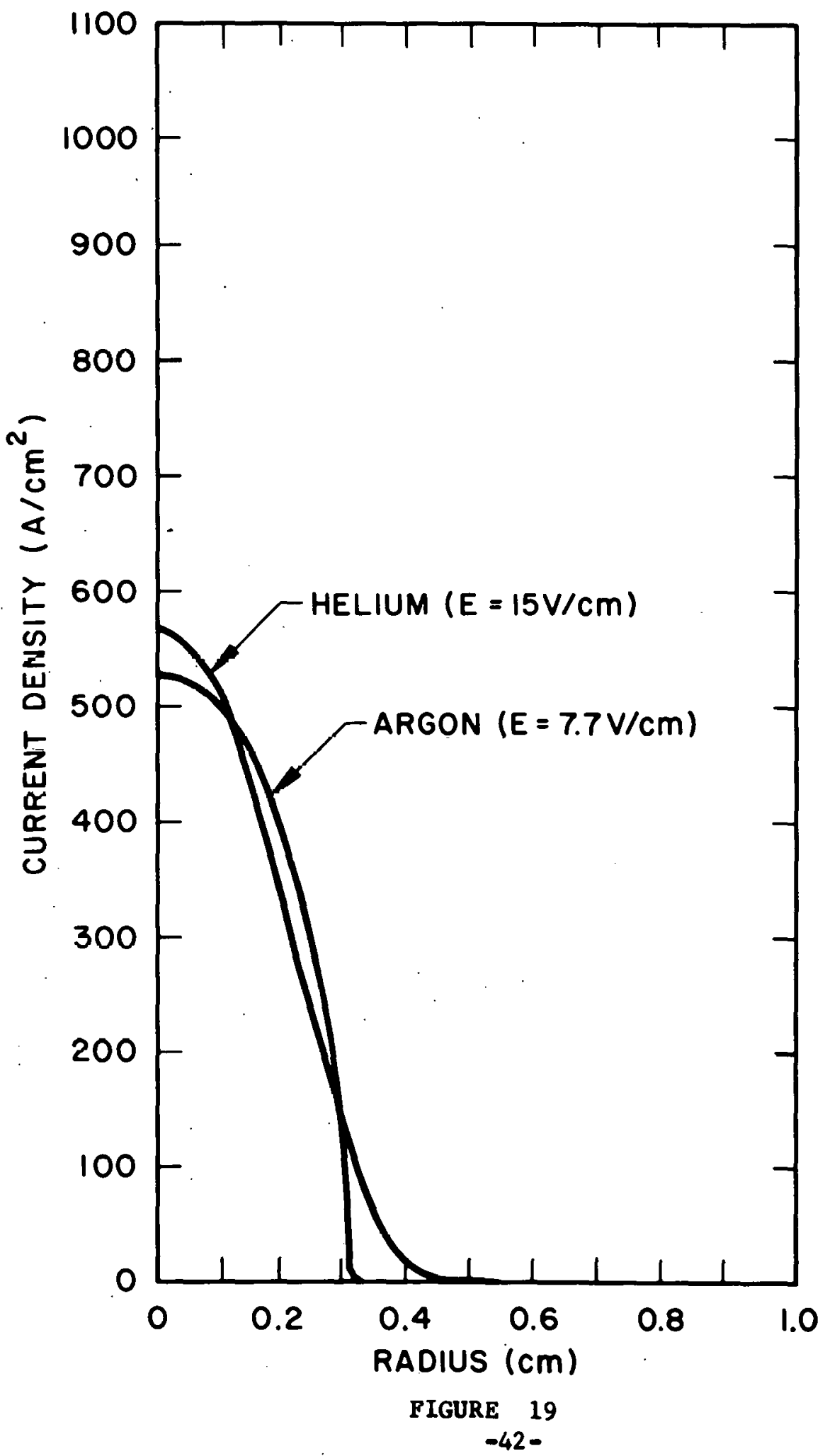


POWER DENSITY DISTRIBUTION

FOR ARGON AND HELIUM ARCS HAVING

THE SAME TOTAL POWER

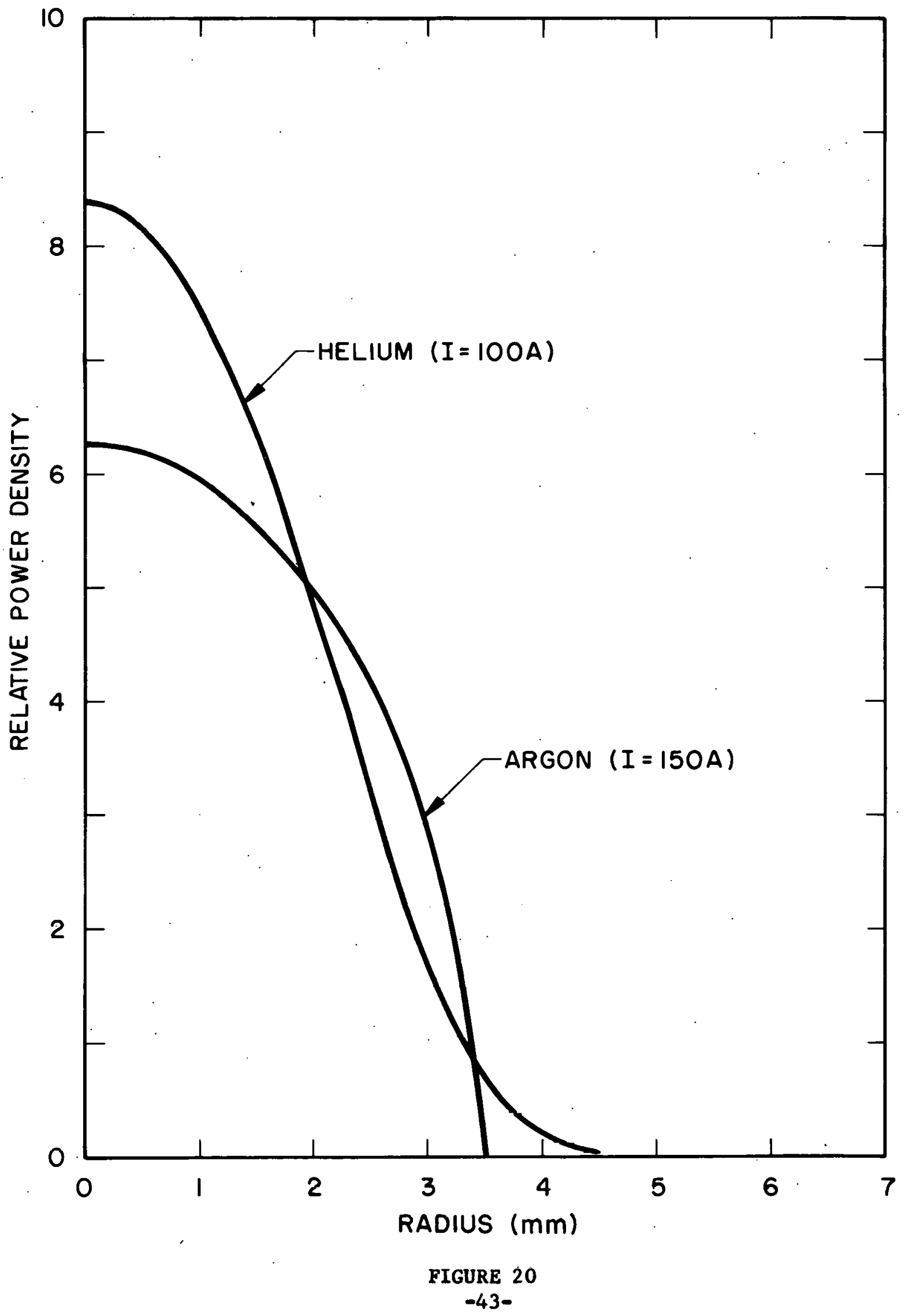




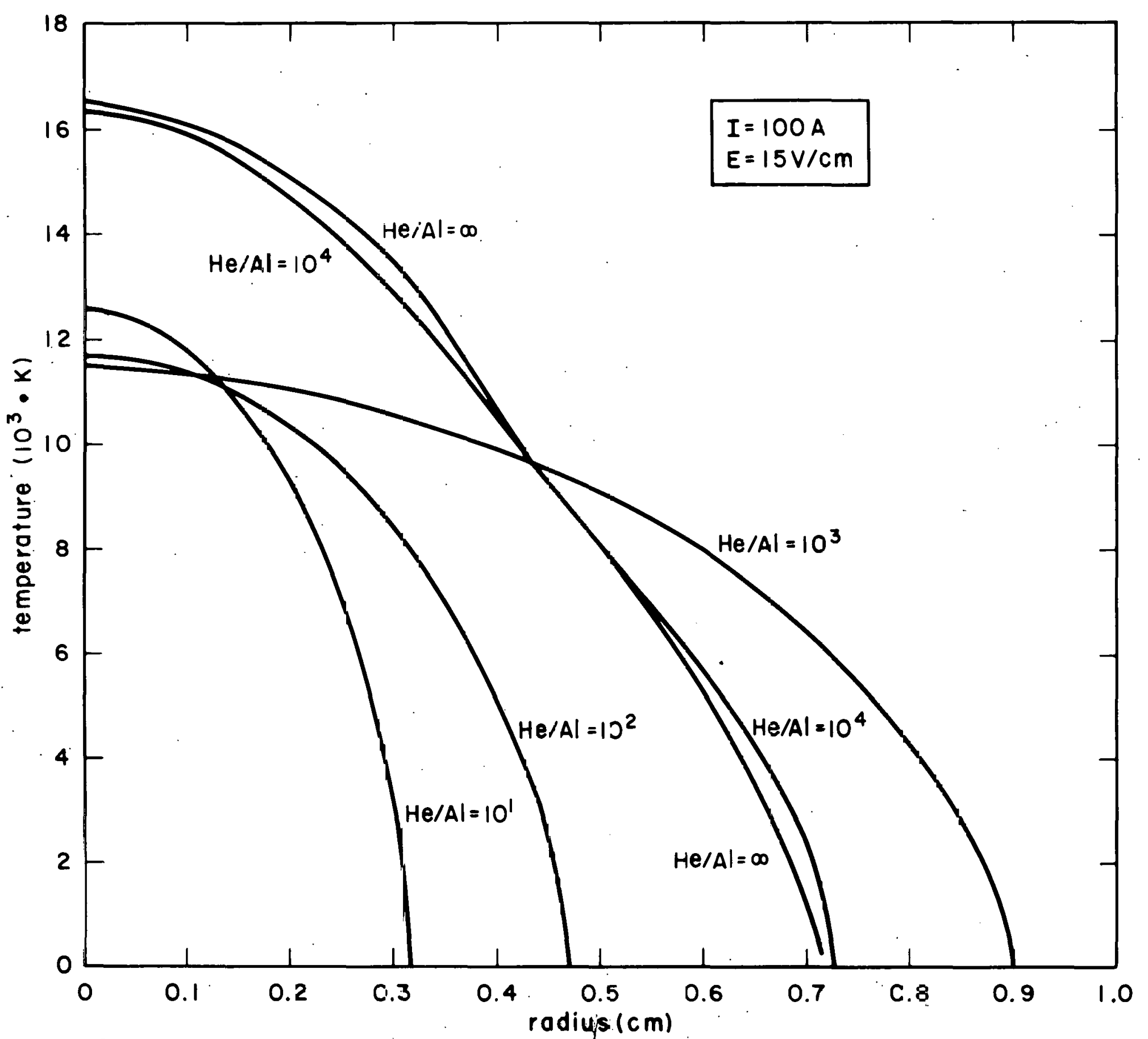

Figure 21. Radial temperature distribution for varimis mixtures of aluminum and he:-ium gas. 


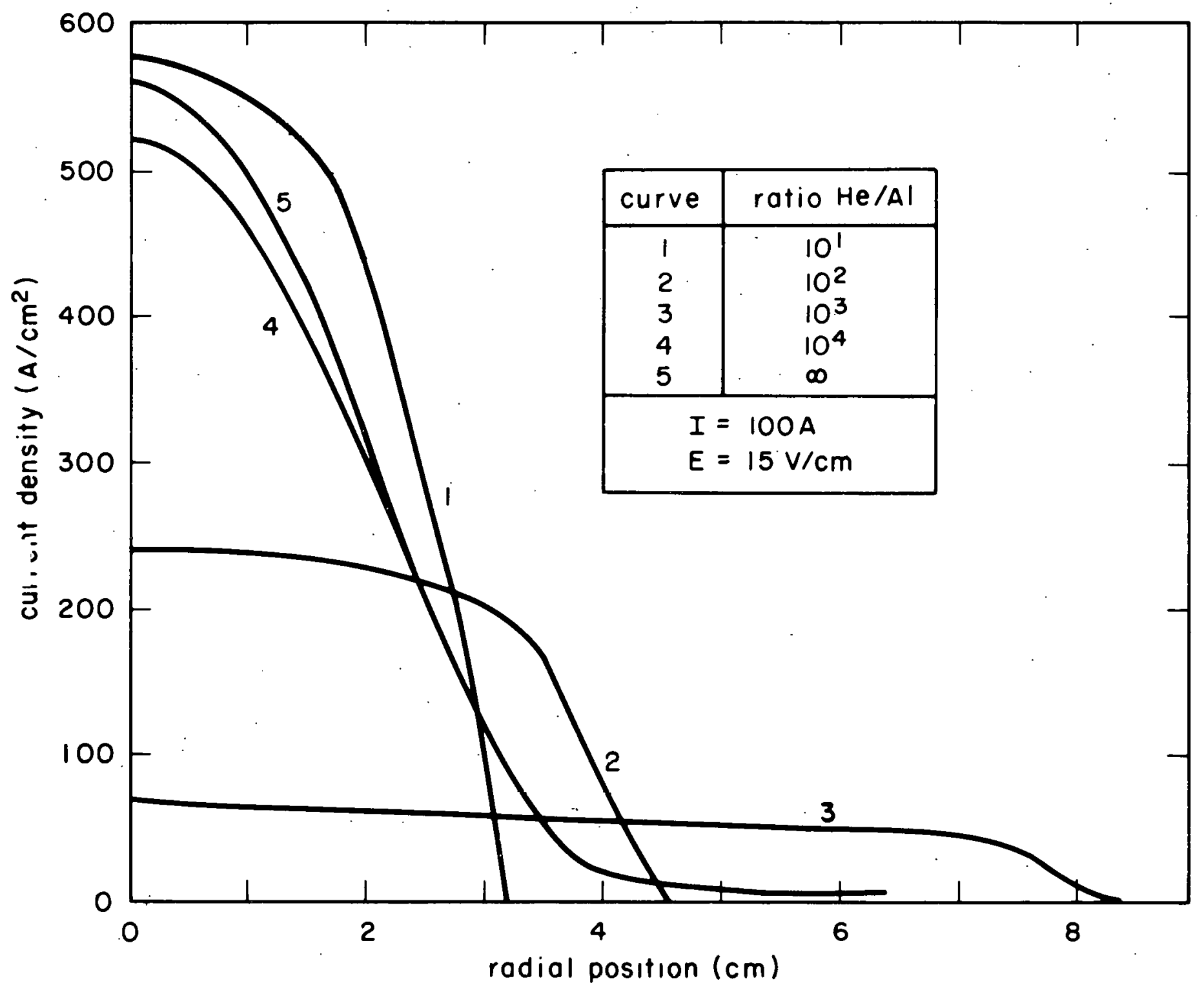

FIGURE 22 - Radial current density distribution for various mixtures of aluminum and hellum gas. 


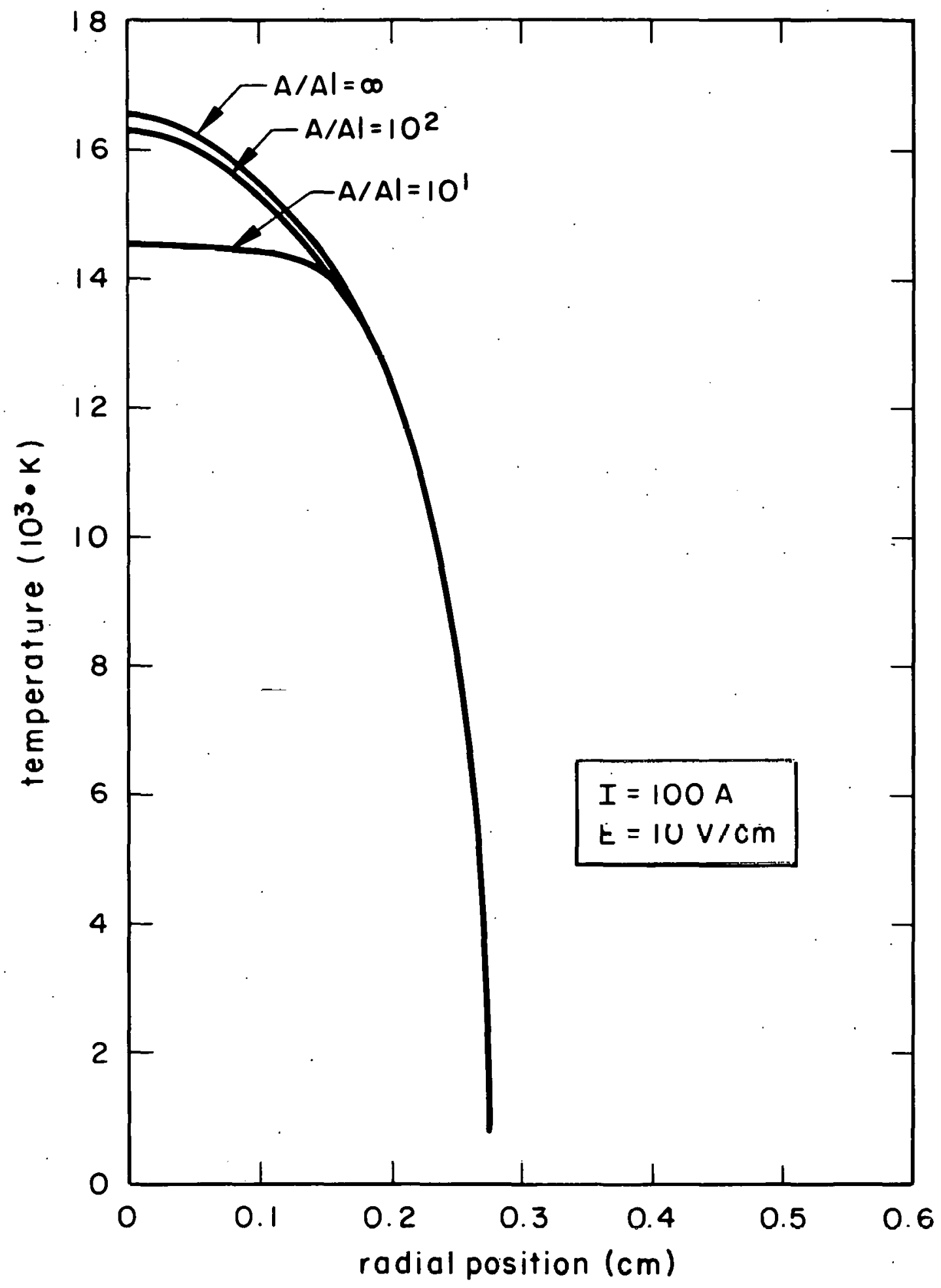

FIGURE 23 Radial temperature distribution for various mixtures of aluminum and
argon gas. 


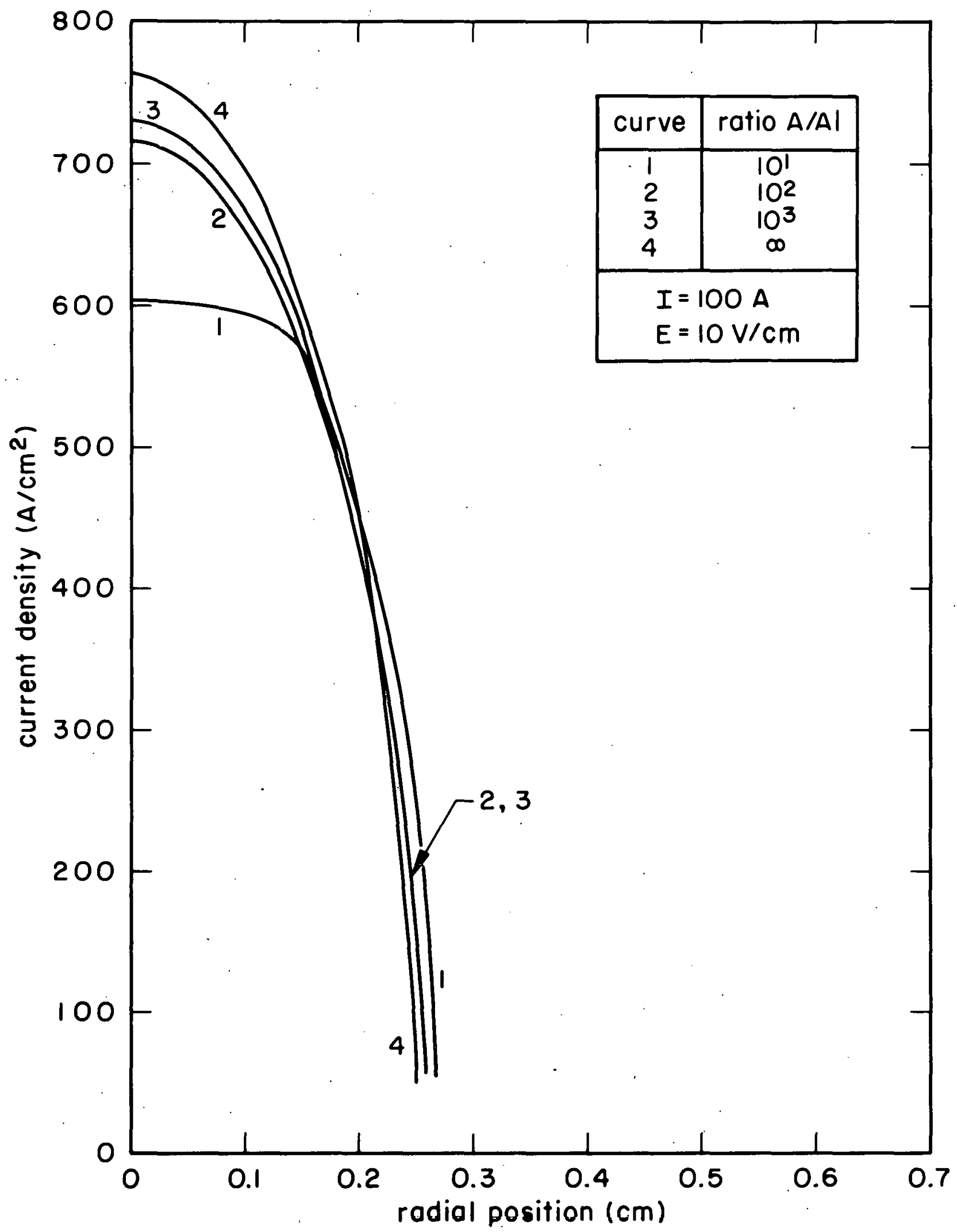

FIGURE 24 Radial current density distribution for various mixtures of aluminum and aryon gas. 


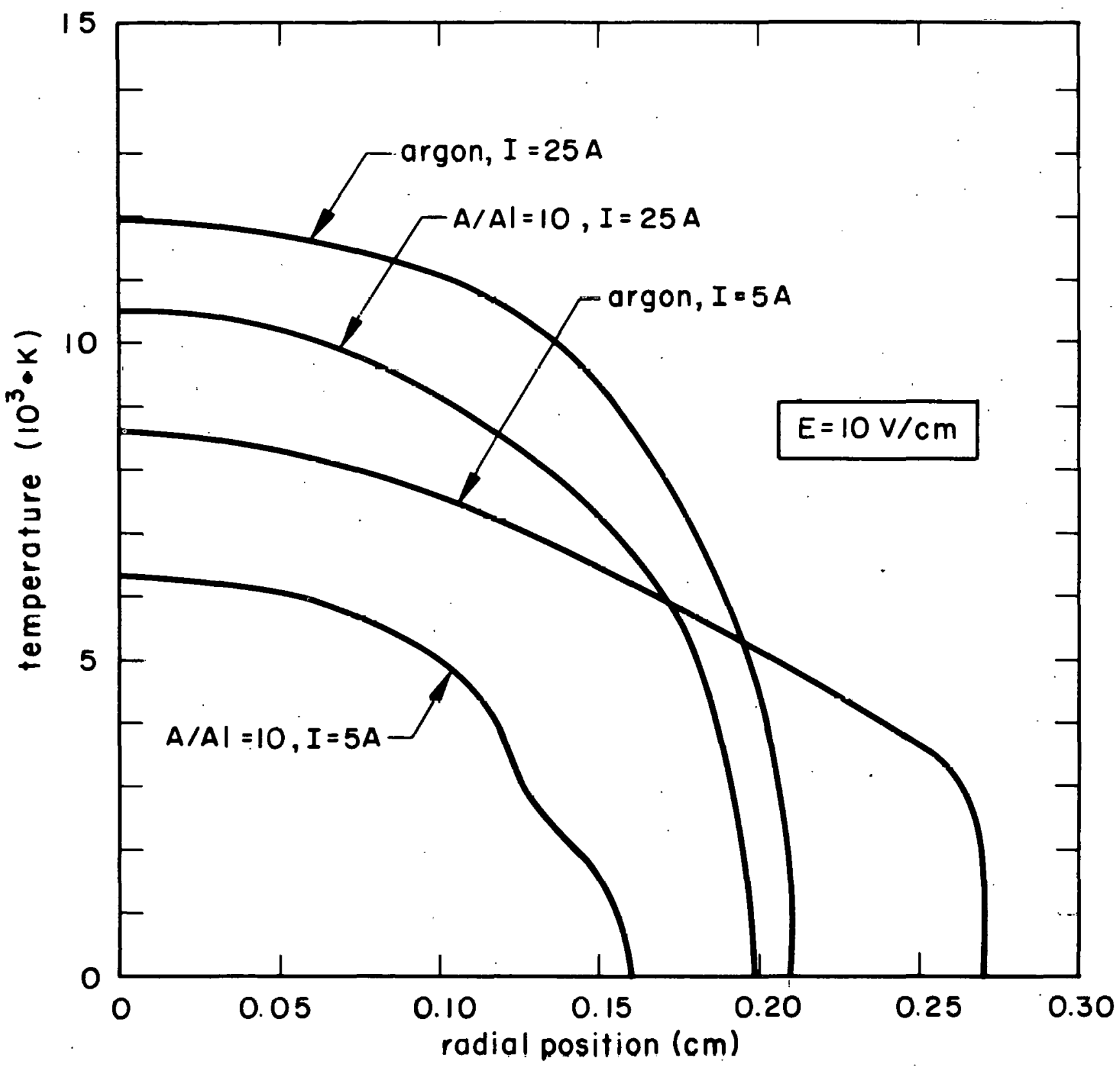

FIGURE 25 Radial temperature distribution for 5 amp and 25 amp argon and argonaluminum arcs. 


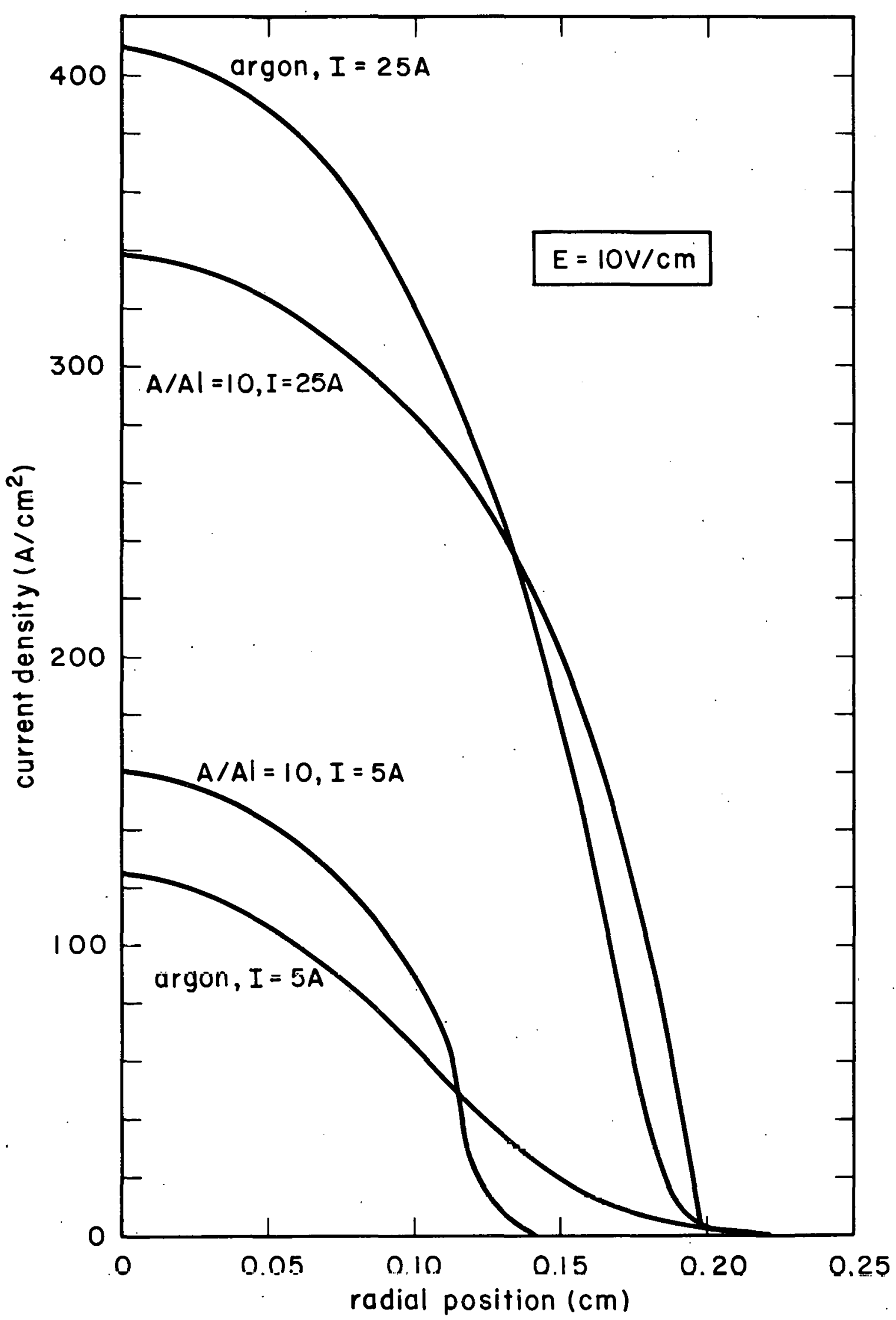

FIGURE 26 Current density distribution for 5 amp and 25 amp argon and argonaluminum arcs. 
TEMPERATURE PROFILE OF A IOOA TIG ARC (GICK ET AL)

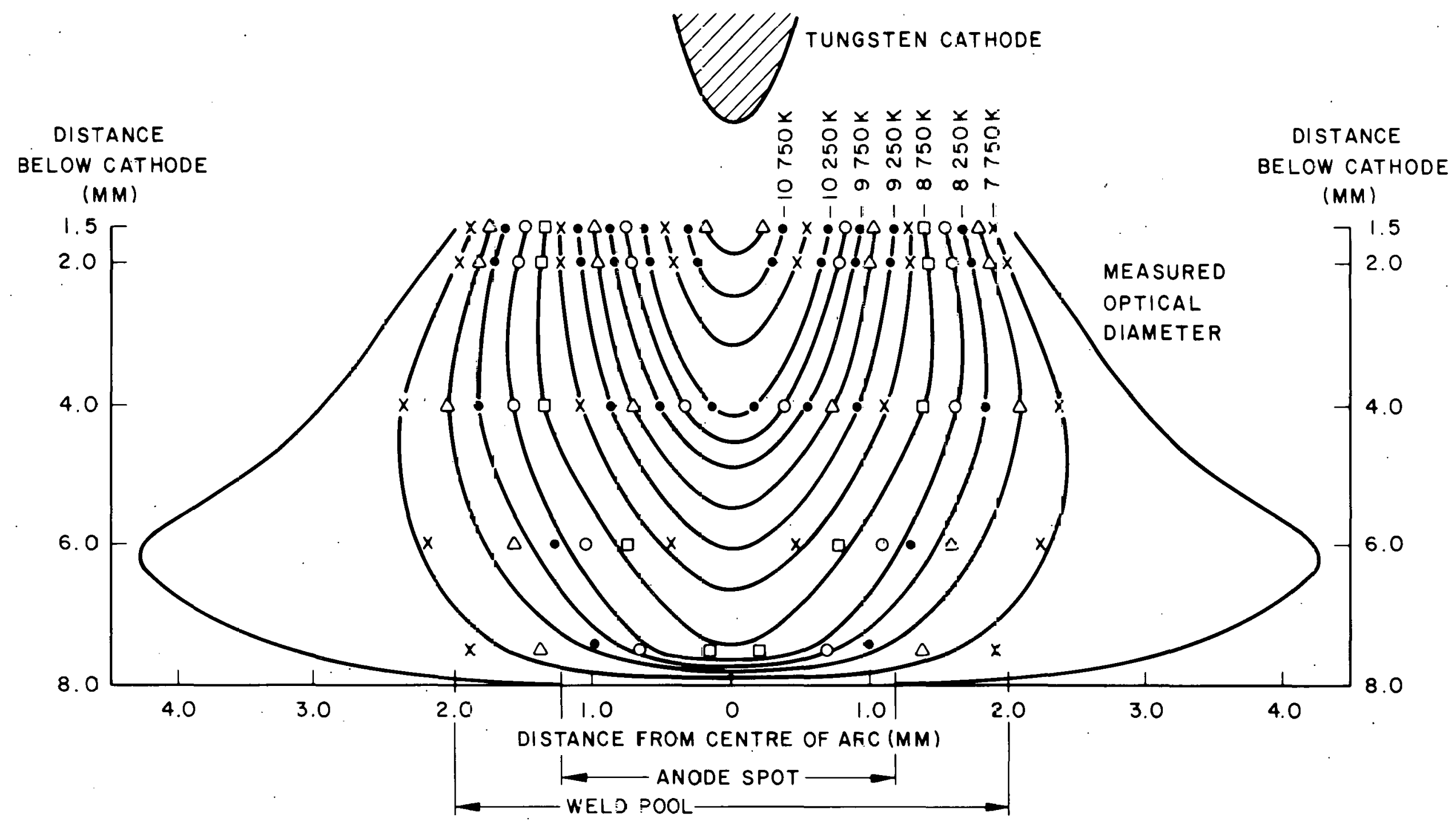

FIGURE 27 
CALCULATED AND EXPERIMENTAL RADIAL TEMPERATURE DISTRIBUTION FOR IOOA ARGON ARC:

EXPERIMENTAL VALUES ARE THOSE MEASURED $4 \mathrm{~mm}$ BELOW CATHODE BY GICK ETAL.

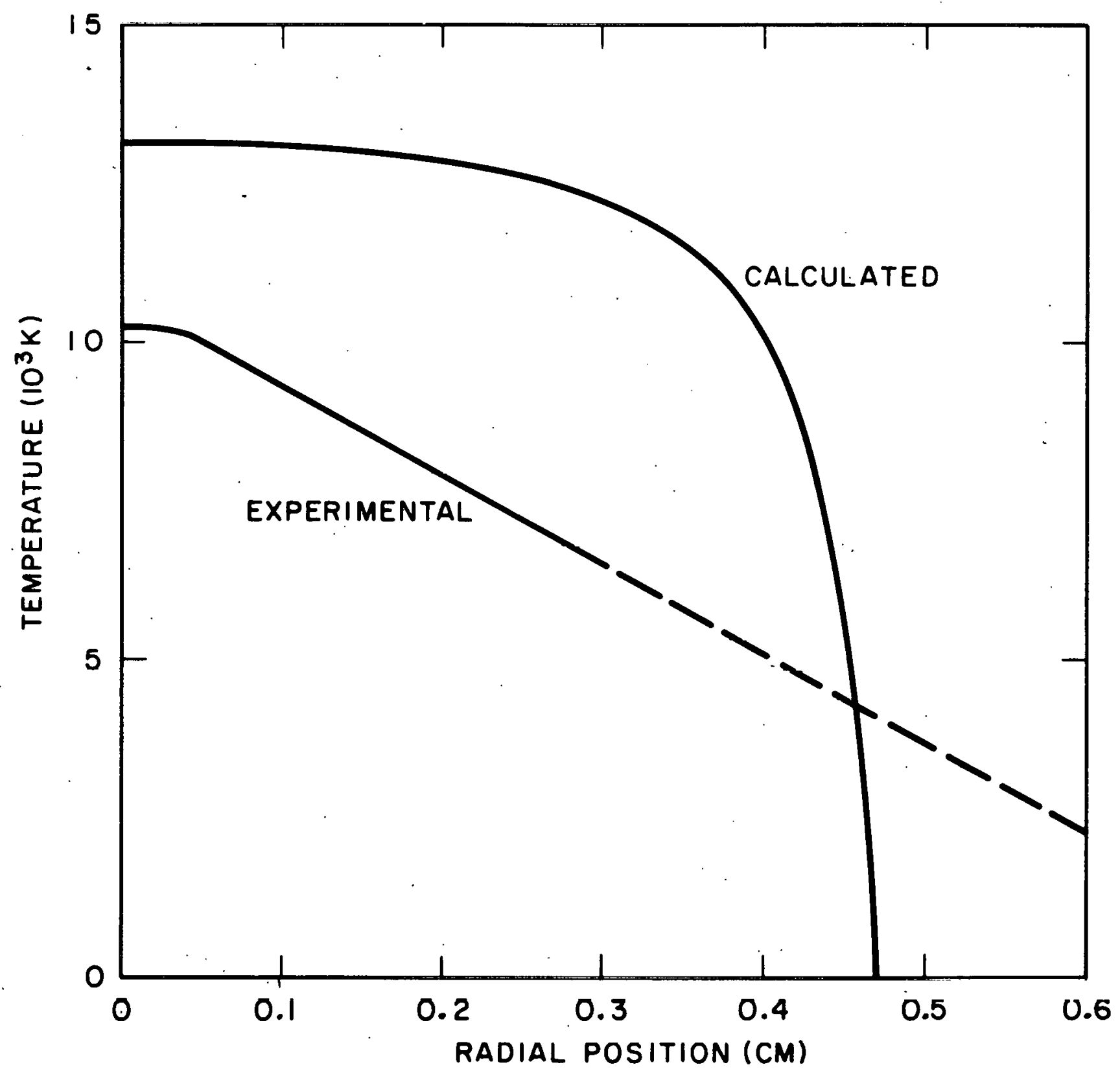

FIGURE 28 
TEMPERATURE DISTRIBUTIONS OF A $6 \mathrm{~mm}, 250$ AMP FREE BURNING ARGON ARC FOR VARIOUS PRESSURES (EVANS-TANKIN)

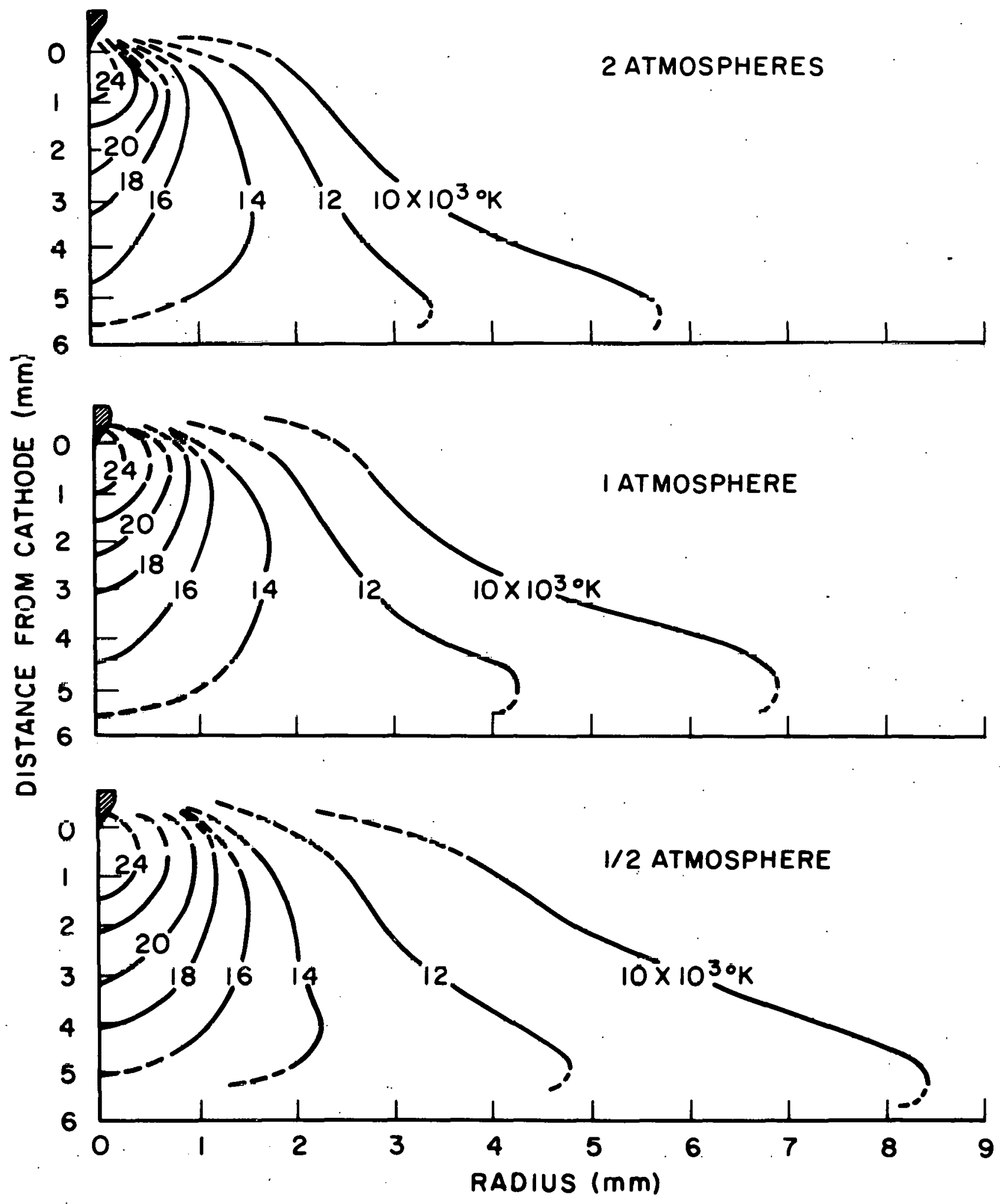

FIGURE 29 


\section{ELECTRIC FIELD INTENSITY AS A FUNCTION OF DISTANCE FROM CATHODE AS DETERMINED FROM ARC TEMPERATURE DATA}

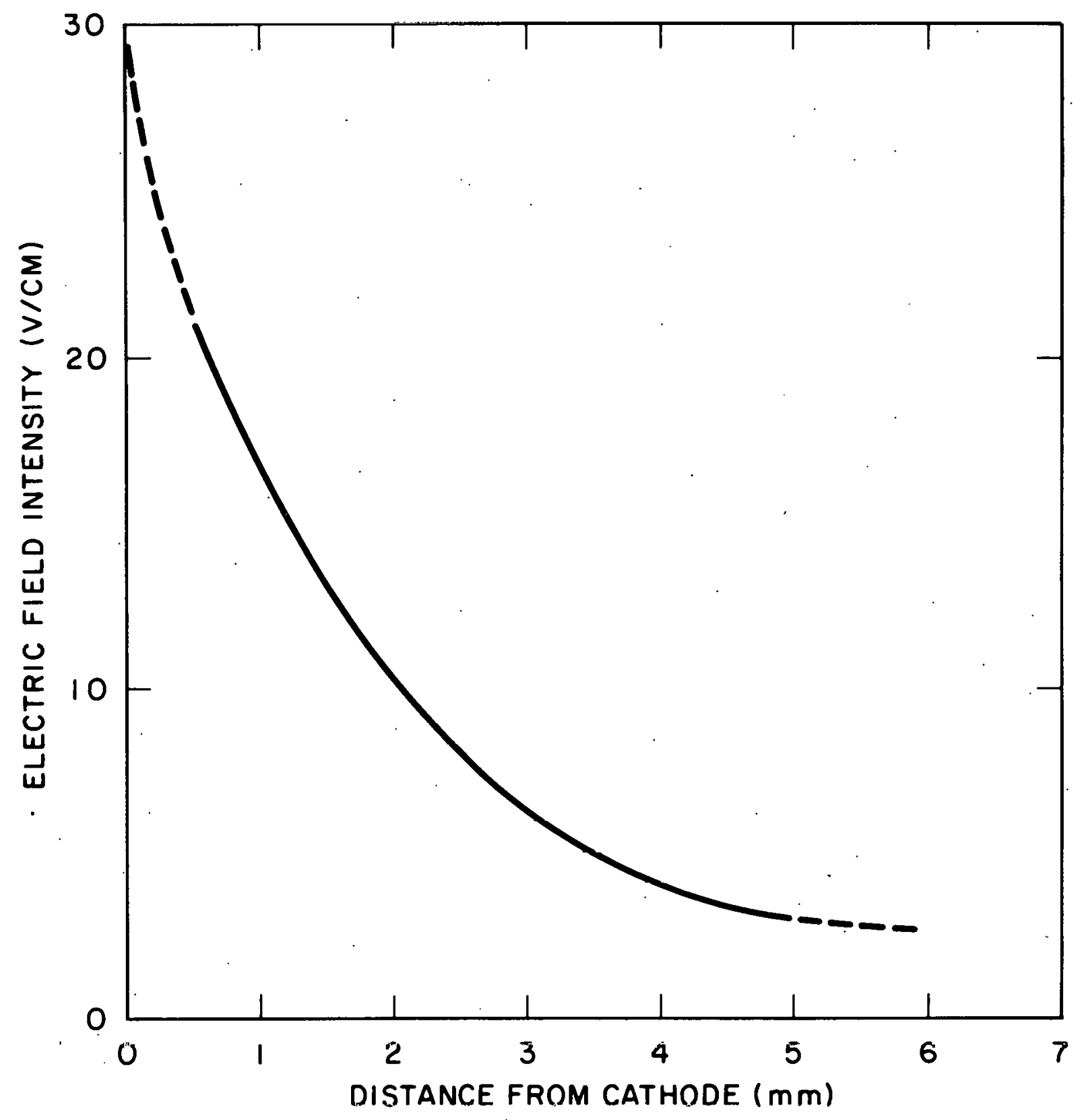

FIGURE 30 
ELECTRIC POTENTIAL AS A FUNCTION OF DISTANCE FROM THE CATHODE. TOTAL ARC VOLTAGE ASSUMED $\simeq \| V \cdot W I T H$ EQUAL ANODE AND CATHODE DROPS

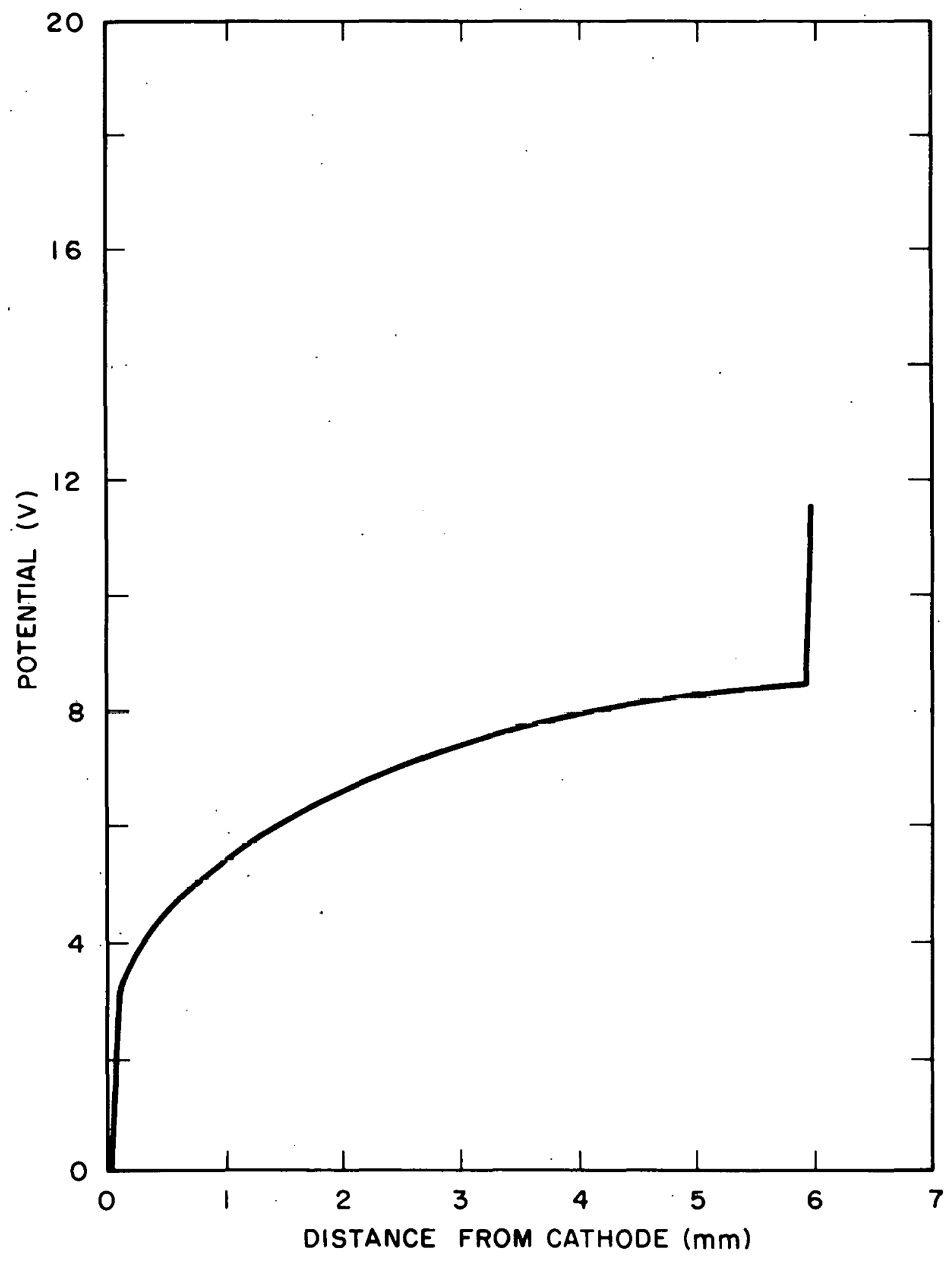

FIGURE 31 


\section{APPENDIX I}

\section{Calculation of Radiation Emission in an Argon Arc}

The radiation term $U$, in Equation (5) represents quantic emission of all the relevant spectral lines from the various species of gases and impurities(13). Figure 11 illustrates the different type radiative transitions that may occur in atoms which contribute to the radiative power. The total power $U$ is given by the summation over the bound-bound transitions $U_{b b}$, free-bound transition $U_{f b}$, and free-free transitions $U_{f f}$

$$
\mathbf{u}=\mathbf{u}_{\mathrm{bb}}+\mathbf{u}_{\mathrm{fb}}+\mathbf{u}_{\mathbf{f f}}
$$

Radlation from bound-bound levels is given in principle by summations over the upper levels $\mathrm{k}$ of the excited atoms from which the radiation is emitted, lower levels to which the atom resides after emission, and a summation over the radiating species (molecular, atomic, lonic, etc.) of index $j$.

This may be written as

$$
\begin{aligned}
u_{b b} & =\sum_{j} \sum_{k} \sum_{l}\left(N_{k} h V_{k l} A_{k l}\right)_{j} \\
N_{k} & =\text { density of excited levels } \\
h & =\text { Planck's constant } \\
\nu_{k 1} & =\text { line frequency } \\
A_{k 1} & =\text { transition probability }
\end{aligned}
$$

The power radiated from free-bound transitions may be described with the following equation

where

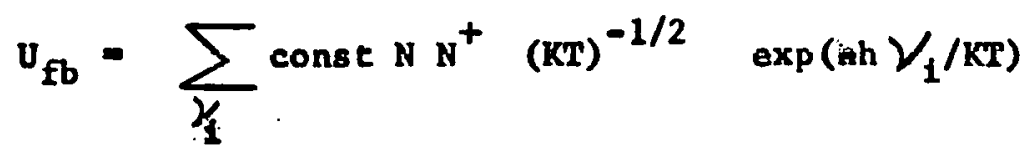

$$
\begin{aligned}
N & =\text { electron number density } \\
N^{+} & =\text {Ion number density } \\
K & =\text { Boltzman's constant }
\end{aligned}
$$


The equation for free-free transitions, also known as Bremmstrahlung is given for the $1^{\text {th }}$ species, by

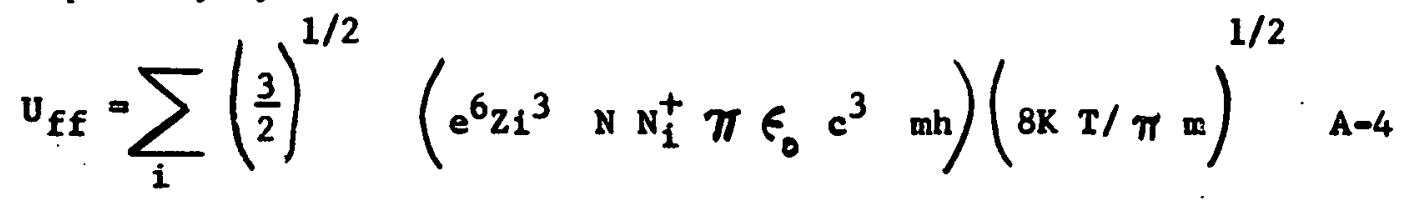$$
z_{1}=\text { degree of ionization of the } 1^{\text {th }} \text { species }
$$$$
\text { c speed of light }
$$$$
\text { e elementary charge }
$$$$
\epsilon_{0}=\text { permittivity of vacuum }
$$$$
m \text { a electron ma'ss }
$$$$
\text { h = Planck constant }
$$

In the majority of the high-pressure arcs (of which the welding arc is so classified), the predominant radiation term results from the bound-bound transitions(13). Although the two types of radiation are important and must be investigated, they will be assumed to be negligible for the first approximation. It will then be shown that these terms must be sma11; in fact the calculated radiation (with no self-absorption) for an argon axc attributed to $U_{b b}$ alone 18 greater than the experimentally observed radiation emission. To evaluate equation A-2 as a function of temperature, the density of excited states is determined. Assuming local thermodynamic equilibrium (LTE) the level density $N_{k}$ is given by

where

$$
N_{k}=N_{j} \frac{g_{k}}{g_{0}} \quad \exp \left(-V_{k} / K I\right)
$$

$$
N_{j} \text { - density of relevant specie in the ground state }
$$

$$
\begin{aligned}
8_{k}, 8_{0} & =\text { statistical weight factors } \\
V_{k} & =\text { excitation potential of state } k \\
k & =\text { Boltzman constant } \\
T & =\text { temperature }
\end{aligned}
$$


The density of lons and atoms is obtained from the Saha relation $S(T),(22)$ :

$$
\begin{aligned}
& S(T)=\frac{N_{i} N_{e}}{N_{a}} \\
& S(T)=2\left(\frac{Z_{+}(T)}{Z_{a}(T)}\right)\left(\frac{2 \pi m_{0} k}{h^{3}}\right) T^{3 / 2} \quad \exp \left(\frac{-E_{0}+E_{0}}{K T}\right)
\end{aligned}
$$

where

$N_{a}=$ number density of neutral atoms

$\mathrm{N}_{1}$ - number density of ionized atoms

$N_{e}=$ number density of electrons

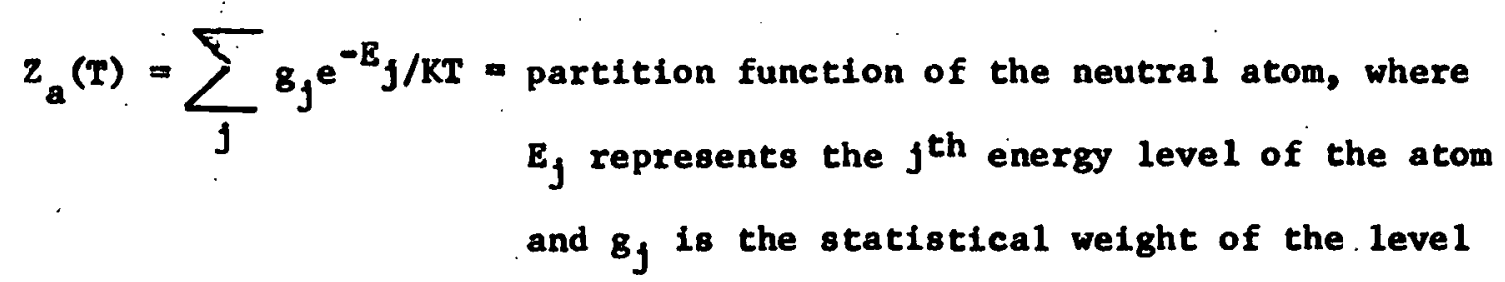

$z_{+}(T)=\sum_{n} B_{n} e^{-E_{N} / K T}=$ partition function of the lonized atom, where $E_{n}$ is the energy of the $n^{\text {th }}$ level of the Ion and $g_{n}$ is the statistical weight of the level

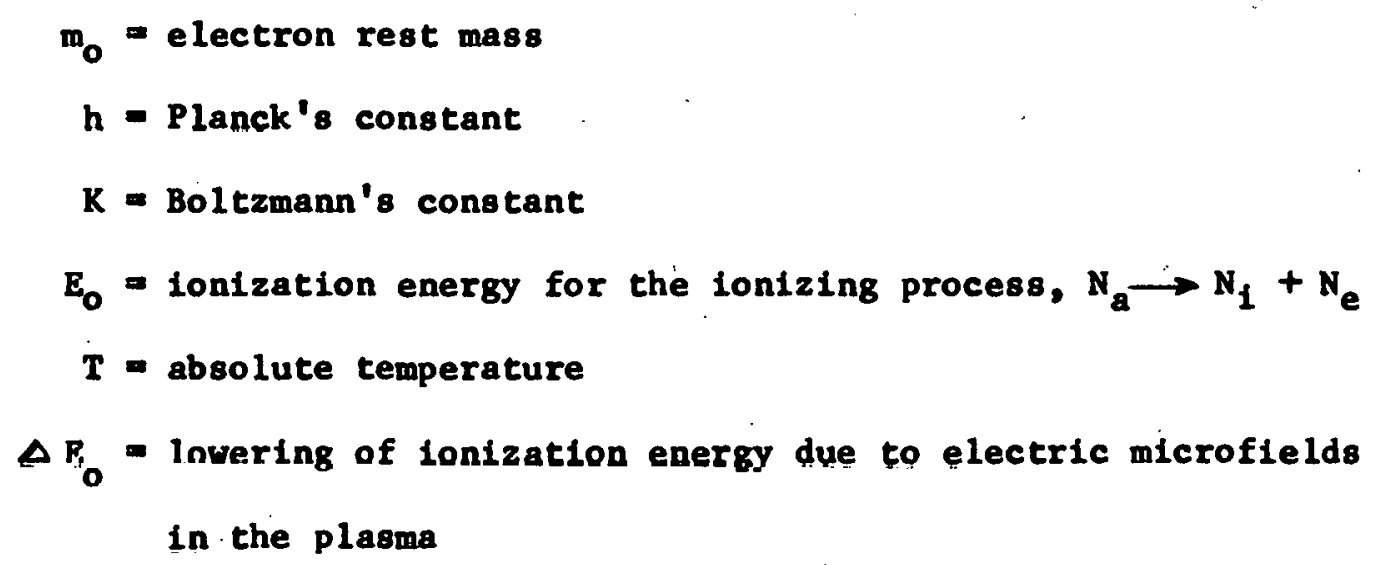


From the gas law,

$$
N_{e}+N_{i}+N_{a}=\frac{P}{R T}
$$

where

$$
\begin{aligned}
& P=\text { pressure } \\
& R=\text { gas constant }
\end{aligned}
$$

Assuming

$$
N_{e}=N_{1},
$$

and using equation $A-6$ and $A-8$, an equation for $N_{e}$ is obtained in the form

$$
N_{0}=S(T)+\left[S(T)^{2}+\frac{P S(T)}{R T}\right]^{1 / 2}
$$

Employing the level and transition probability data from Reference 23 and partition function data of Reference 22, radiation $1088 e 8$ attirbuted to bound-bound transitions in argon from neutral (ArI) and singly ionized (ArII) argon atoms were calculated for the 687 wavelengths listed. The results are shown in Figure A-1 along with experimental data of Evans and Tankin(14). The calculational results obtained from equation A-2 overestimate the radiation loss from the argon arc. This is attributed to the inclusion of strong ultra-violet (UV) emission. At the temperatures of concern, the arc should be considered optical ly thick in the ultra-violet region. Under such conditions, the UV is absorbed within the arc boundary and re-emission of the radiation must be considered to occur throughout the arc region. The results of omitting the UV completely are shown in Figure A-2. Precise calculations that consider re-emission become extremely difficult for the 
optically thick case. In addition, free-bound and Bremmstrahlung contributions to the radiation term still need to be considered. As a result of these calculational difficulties, the experimental radiation data of Evans and Tankin(14) was used exclusively for evaluating the effects of the radiation term on the one-dimensional temperature and current density distributions of an argon arc. 
TEMPERATURE DEPENDENT RADIATION INTENSITY FOR ARGON AT I ATMOSPHERE PRESSURE

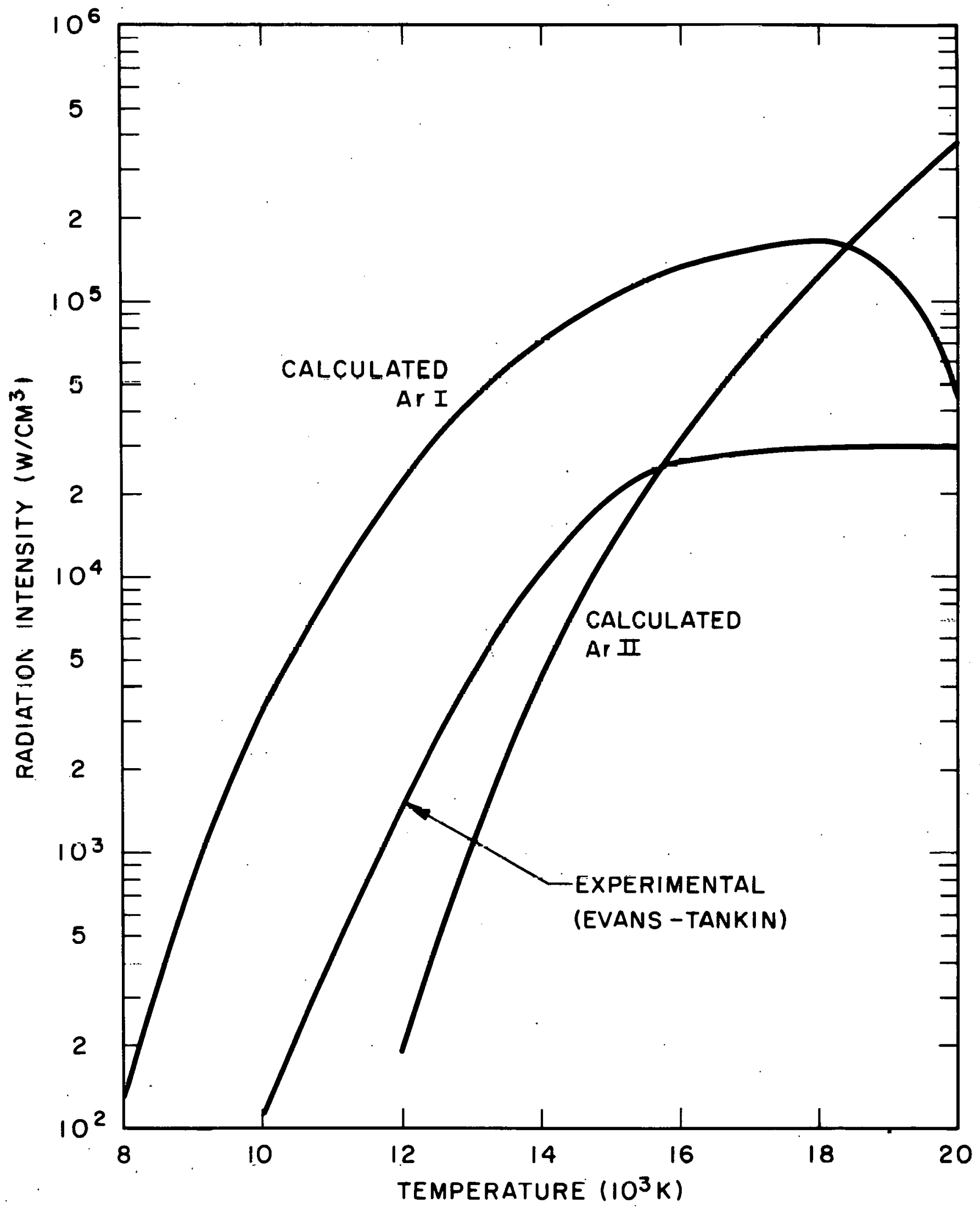

FIGURE Al 
TEMPERATURE DEPENDENT RADIATION INTENSITY FOR ARGON AT I ATMOSPHERE PRESSURE

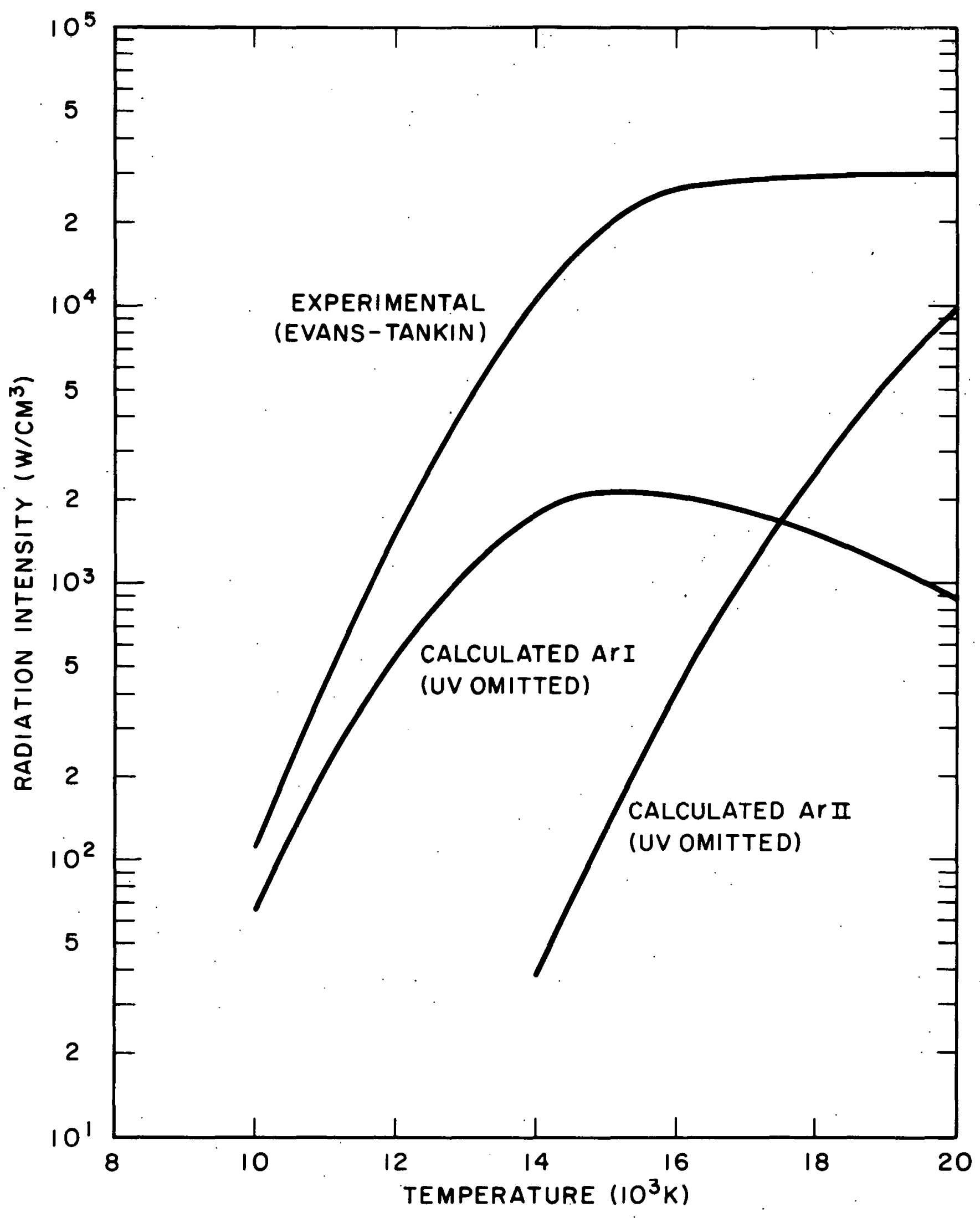

FIGURE A2 